University of Rhode Island

DigitalCommons@URI

Open Access Master's Theses

1995

\title{
Childhood Sexual Experiences and Adult Funtioning
}

Patricia Lee

University of Rhode Island

Follow this and additional works at: https://digitalcommons.uri.edu/theses

\section{Recommended Citation}

Lee, Patricia, "Childhood Sexual Experiences and Adult Funtioning" (1995). Open Access Master's Theses. Paper 1727.

https://digitalcommons.uri.edu/theses/1727

This Thesis is brought to you for free and open access by DigitalCommons@URI. It has been accepted for inclusion in Open Access Master's Theses by an authorized administrator of DigitalCommons@URI. For more information, please contact digitalcommons-group@uri.edu. 
CHILDHOOD SEXUAL EXPERIENCES AND ADULT FUNCTIONING

BY

PATRICIA LEE

A THESIS SUBMITTED IN PARTIAL FULFILLMENT OF THE

REQUIREMENTS FOR THE DEGREE OF

MASTERS OF ARTS

IN

PSYCHOLOGY

UNIVERSITY OF RHODE ISLAND

1995

$2100 \%$ 


\begin{abstract}
The purpose of this study was to examine the long term relationship of childhood sexual abuse to school performance, perceptions of school ability, and adult functioning in college women. This investigation found that women who indicated a history of childhood sexual abuse had significantly more problems in psychosocial functioning and reported less social support than women who did not indicate childhood sexual abuse. Interestingly the sexually abused group (SA) did significantly better on 9th grade grade point average (GPA) than the non-sexually abused group (NSA). However, this trend, though not significant, reversed itself by the 11 th grade. In addition the NSA group had a significant linear GPA trend, whereas the SA group had a significant quadratic trend. Generally there were no significant differences found between the two groups regarding learning styles and school perceptions. In general, the results of this study support and extend prior research in the area of sexual abuse and indicate the need for attention regarding issues and interventions for women who were abused as children. Future directions and limitations of this current study are discussed.
\end{abstract}




\section{Acknowledgment}

I would like to thank my major professor, Dr. Patricia J. Morokoff for her hours of dedication and encouragement throughout this project. Her tremendous support enabled this process to be a valuable learning experience.

I would also like to thank the rest of my committee members who supported me in my effort to complete this research. I am extremely grateful to Dr. Denise Dezolt for helping me see the implications of this study from a school psychology perspective. In addition, Dr. Gene Knott provided valuable feedback that was incorporated into this thesis.

I wish to also thank my parents, Marie and Arthur Lee, for their love, support, and guidance. None of this would have been possible without their encouragement and belief that I could accomplish anything. 
Table of Contents

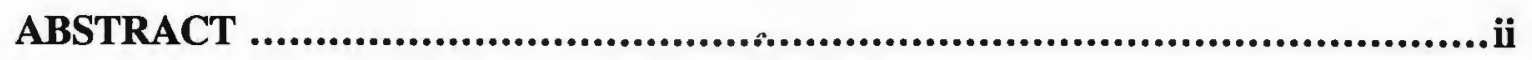

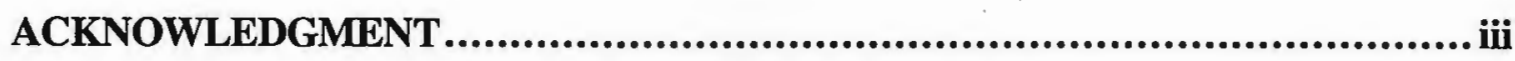

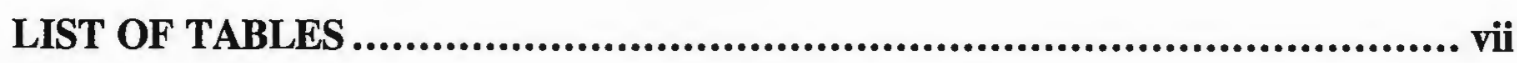

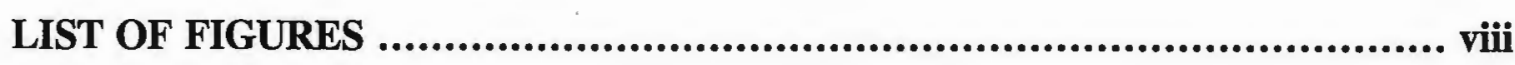

LIST OF PROTOCOLS IN APPENDIX A............................................ viii

LIST OF MEASURES IN APPENDIX B ............................................ viii

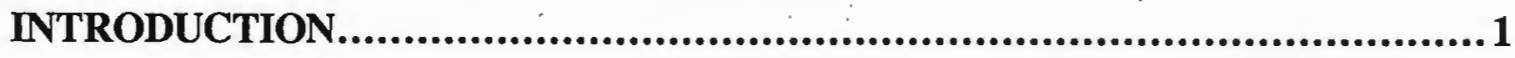

STATEMENT OF THE PROBLEM .............................................................

JUSTIFICATION FOR AND SIGNIFICANCE OF THE STUDY .......................1

PREVALENCE OF SEXUAL AbUSE ................................................. 2

Problems with Measuring Prevalence of SEXual Abuse......................... 3

Characteristics of SeXual AbusE ............................................... 5

RELIABILITY OF REPORTING OF SEXUAL ABUSE .................................... 7

NEGATIVE FEELINGS AND ASPECTS OF SEXUAL ABUSE....................8

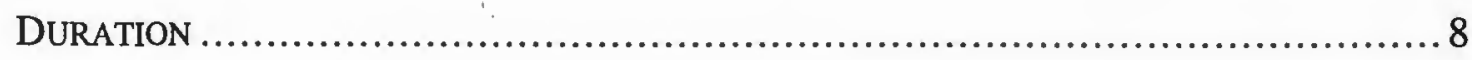

DISCLOSURE ................................................................... 9

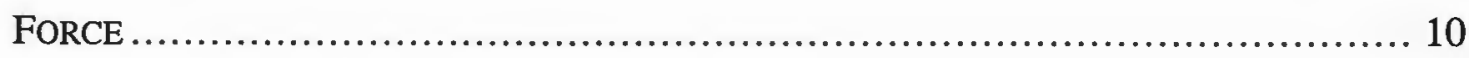




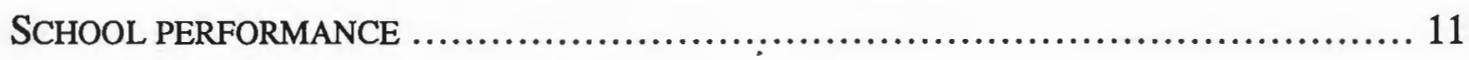

SCHOOL PERCEPTION............................................................. 16

LEARNING AND SEXUAL ABUSE............................................. 16

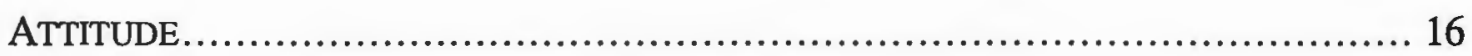

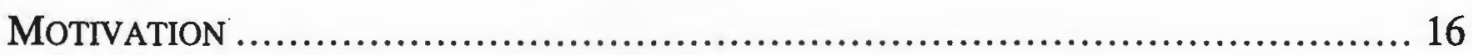

ANXIETY .................................................................... 17

CONCENTRATION ..................................................................... 17

ADULT PSYCHOLOGICAL FUNCTIONING .................................. 17

DISSOCIATION ................................................................. 18

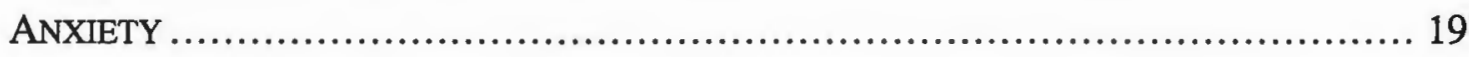

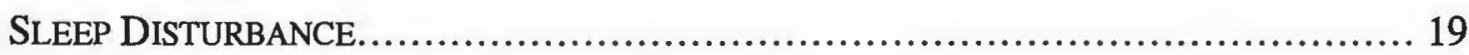

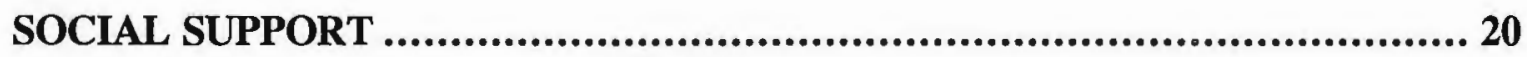

GENERAL STUDY GOALS .................................................... 22

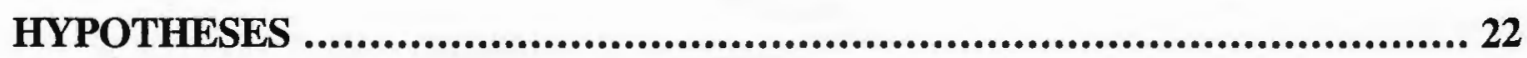

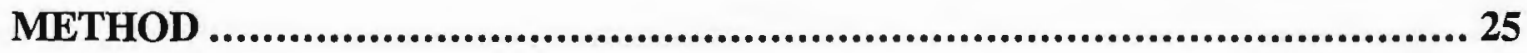

PARTICIPANTS ................................................................... 25

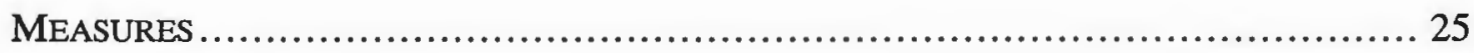

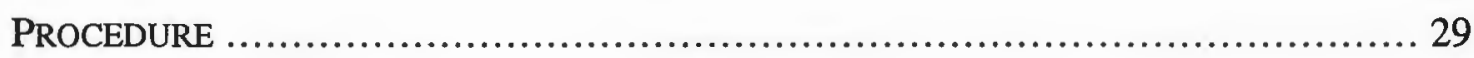




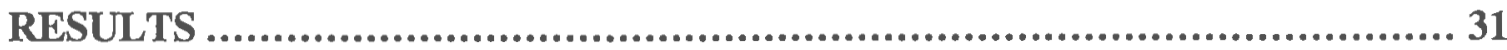

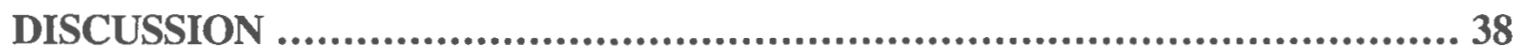

LIMITATIONS OF THE STUDY ................................................. 44

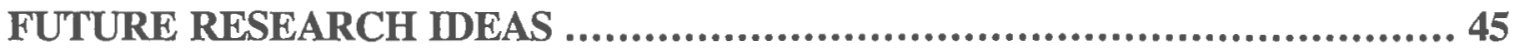

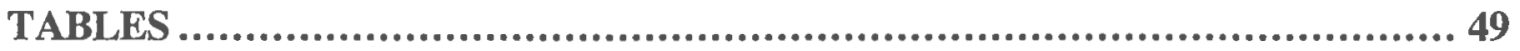

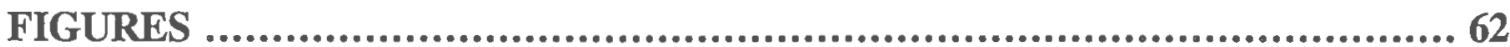

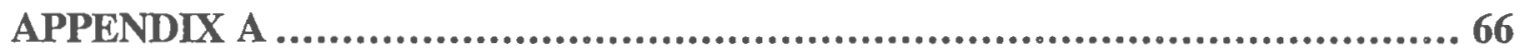

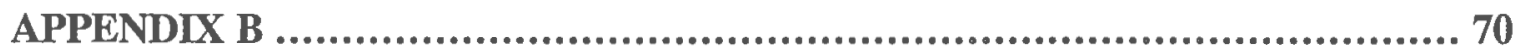

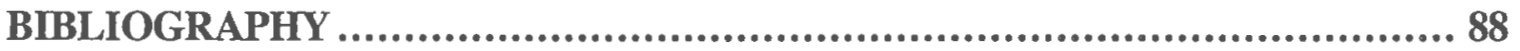




\section{List of Tables}

TABLE 1: Descriptive Data FRom AbUSED AND Non-ABUSED PARTICIPANTS.......... 49

Table 2: SeXual AbUSE Data for AbUSEd Participants ........................... 51

TABLE 3: MEANS AND STANDARD DEVIATIONS FOR ABUSED $(\mathrm{N}=50)$ AND NON-ABUSED

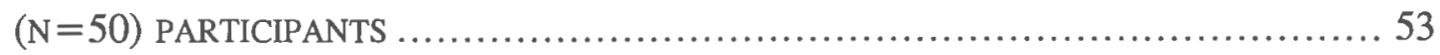

TABLE 4: SUMMARY OF STUDY PREDICTIONS AND OUTCOMES ........................... 54

TABLE 5: INTERCORRELATIONS OF MEASURES FOR ENTIRE SAMPLE...................... 56

TABLE 6: INTERCORRELATIONS OF MEASURES FOR SUBSAMPLE OF ABUSED AND NONABUSED

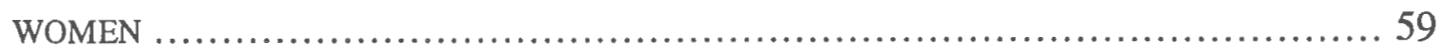


List of Figures

FIGURE 1: MEANS OF SCHOOL MEASURES FOR ABUSED AND NONABUSED PARTICIPANTS .. 62

FIGURE 2: MEANS OF SCHOOL MEASURES FOR ABUSED ( 7 \& UNDER,; 8 \& OVER) AND NONABUSED PARTICIPANTS 64

List of Protocols in Appendix A

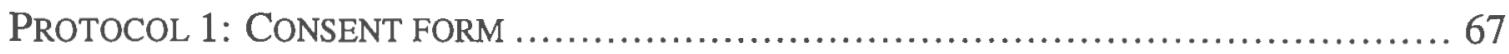

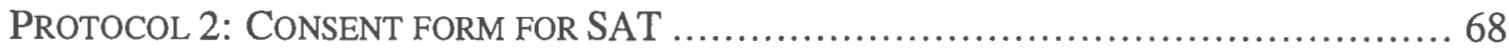

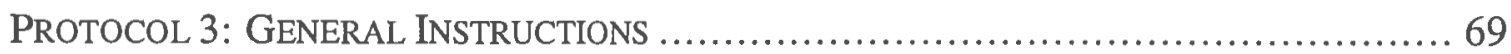

List of Measures in Appendix B

MEASURE 1: BACKGROUND INFORMATION ......................................... 71

MEASURE 2: THERAPY QUESTIONS ................................................ 71

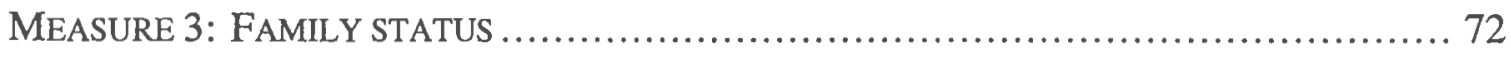

MEASURE 4: SELF-REPORT Of SCHOLASTIC APTITUdE TeSt (SAT) .................... 74

Measure 5: Self-RePort of High School Grade Point Average (GPA)........... 74

Measure 6: The Self-Perception Profile for College Students (Neemann, J., \&

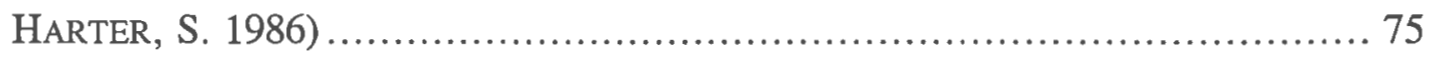

Measure 7: The Learning AND Study Strategies InVEnTory (LASSIE: Weinstein,

PALMER, \& SCHULTE, 1987) ............................................... 76

Measure 8: The Trauma Symptom Checklist (TSC-33) (BrieRe \& RunTZ 1987) ... 78 Measure 9: Sexual Assertiveness Scale (Quina, Harlow, Gibson, \& Morokoff,

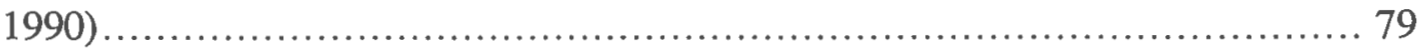


Measure 10: SeXual Communication SCALE (Dieter, 1993 ) ...................... 80

MEAsure 11: SeXual AbUSE INVENTORY (FinKELHOR 1974) ........................ 81

MEASURE 12: TRANSTHERETICAL Model Staging QUESTIONS ....................... 84

MEASURE 13: Social SuPPort (VAUX, RIEDEL, \& STEWART 1987) .................... 85 
Introduction

\section{Statement of the Problem}

The purpose of this study was to examine the relationship of childhood sexual abuse to later school performance, perceptions of school ability, and adult functioning in college women. Women who indicated a childhood sexual abuse experience (both contact and noncontact) were included in the sexual abuse group, and those who failed to indicate abusive histories were assigned to the control group. Both groups consisted of undergraduate women enrolled in general psychology classes of the University of Rhode Island. There have been many empirical studies that have shown a relationship between childhood sexual abuse and behavioral and emotional difficulties. However, none of the research has looked at school performance, school perceptions, and later adult functioning simultaneously nor included women's learning styles. Furthermore, none of the previous research has examined the long term relationship between childhood sexual abuse and subsequent high school and college academic functioning. Justification for and Significance of the Study

Cognitive and psychodynamic theorists generally believe that people make crucial assumptions about themselves, others, the environment, and the future based upon childhood learning (Briere, 1992). Since the experiences of child abuse victims are usually negative, these assumptions and self-perceptions tend to be distorted. People who have experienced childhood abuse may underestimate their own self-efficacy and selfworth.

Furthermore, it has been shown that even when children are indirectly exposed through observation of traumatic events, they may concurrently demonstrate lower self- 
esteem and declines in cognitive and school performance (Bell \& Jenkins, 1991). In the case of sexual abuse the trauma experienced by the child is direct, rather than indirect. After being told frequently that they are "bad" and deserved the abuse, children may internalize this negative self-image. This negative self-image may in turn lead to negative perceptions about their intellectual or scholastic abilities, and cause them to develop ineffectual learning styles.

Another aspect of the sexual abuse experience it that it emphasizes the child's value as a sexual partner rather than for his or her cognitive ability. In addition, these children learn that the only way to obtain what they want is through sexual control, manipulation, and exploitation, rather than through developing their skills academically.

Prevalence of Sexual Abuse. National statistics have indicated that there are 100,000 to 500,000 children sexually abused each year (Witchel, 1991). Finkelhor, Hotaling, Lewis, and Smith (1990) found a prevalence rate for childhood sexual abuse of $27 \%$ for women and $16 \%$ for men in a national survey of adults conducted by the Los Angeles Times. Furthermore they showed that when only sexual abuse that involved intercourse was tallied, the rate was $13 \%$ for women and $9 \%$ for men. Briere and Runtz (1986) reported a $15 \%$ prevalence rate of childhood sexual abuse for college populations. Finkelhor (1979) reports $19 \%$ of college women in the New England area have been victims of abusive sexual contacts by 17 years of age. There have been several empirical studies that investigated the prevalence of sexual abuse, and regardless of the methodology used, all have shown that sexual abuse is very prevalent in the United States. 
Sexual abuse experiences for both boys and girls cluster around the preadolescent period (Finkelhor, 1979). Mannarino and Cohen (1986) found that out of 45 sexually abused children, half were abused before the age of five. In contrast, Blum, Harmon, Harris, Bergeisen, and Resnick. (1992) found that prevalence rates increase with the female's age. They had 13,454 native Indian nonurban high school students fill out an adolescent health survey. They found that the sexual abuse prevalence was $13 \%$ and that prevalence increased with age, with $21.6 \%$ of females reporting sexual abuse by the 12 th grade. Of those who reported sexual abuse, at least twice as many compared to the nonabused students indicated running away once or twice.

Cupoli and Sewell (1988) found that out of 1,059 patients ages 3 months to 16 years that came to the Pediatric Emergency Room with the chief complaint of sexual abuse, 940 (88.8\%) were females and $119(11.2 \%)$ were males. Confirmation of the chief complaint by results of physical exams or by legal investigation was not always available. In their population there was a high percentage of young victims $42 \%$ were under 7 years of age. Sexual abuse was usually done at the hands of an adult known to the child, who continued to be near the child, placing the child at continued risk. Also, the episodes of sexual abuse for this population were serious and usually involved penetration.

Problems with Measuring Prevalence of Sexual Abuse. A major difficulty with sexual abuse studies is that researchers use different definitions of sexual abuse, which cause prevalence rates for abuse to fluctuate. Wyatt and Peters (1986) contrasted three definitions of sexual abuse for their consideration of the age discrepancy between the victim and perpetrator and the types of behaviors examined between nonfamily and family members. They concluded that asking several activity-specific questions leads to a 
higher rate of reported occurrence than asking one or a few questions. They recommend data collection on all abuse experience regardless of the type of sexual behavior, the age difference between the perpetrator, or their relationship to each other, with the exception of consensual incidents with peers. The advantage to this approach is that analyses can always be modified to fit more restricted definitions, although a disadvantage is the increased cost.

The literature also indicates that the reported prevalence rate is affected by the manner in which subjects are asked to disclose past childhood sexual experiences (Blum et al., 1992; Finkelhor, 1979; Mannarino \& Cohen, 1986; Mrazek, Lynch \& Bentovim 1983).' Wyatt and Peters (1986) suggested that direct personal querying of a client will result in a higher reporting rate than the standard paper and pencil methods of information collection. However, Stinson and Hendrick (1992) found no significant difference in the prevalence rates between clients of a college counseling center who were directly queried and from those where the information was expected to arise during the course of treatment.

Hunter, Kilstrom, and Loda's (1985) findings of masked sexual abuse victims, children who presented with symptoms in absence of admission of sexual abuse, suggested that the prevalence of child sexual abuse is much greater than is readily apparent. Furthermore, they discovered how important it is to consider the possibility of sexual abuse of the siblings of victims, which would increase prevalence rates. Frequently the conversion symptoms were coupled with decreasing performance in school or other evidence of depression. 
Another reason prevalence is so difficult to measure accurately is because much of childhood sexual abuse escapes detection. Corroborating evidence, like suggestive injuries, semen or infection, is found in less than one third of the victims (Mann, 1985). In addition, criminal convictions are rarely obtained due to evidentiary problems, which puts many victims at risk for future abuse (Whitehead, 1992). Also, many victims might never disclose, or when they do, many might not be believed.

Younger children were 12 times less likely to identify the perpetrator, more likely to have a sexually transmitted disease as a sign of abuse, and less likely to give an outcry of sexual abuse at intake. Unfortunately many abused children are young. In a study of 138 children who met the state's criteria for confirmed sexual abuse from La Rabida Children's Hospital in California during 1979 to 1987, about one-third of the children were under 4 years of age (Jaudes \& Morris, 1990).

Characteristics of Sexual Abuse. Sexual abuse crosses all social, economic and racial boundaries. There have been many studies concerning sexual abuse that used both community and clinical samples of adults, of various ages, educational levels, and ethnic backgrounds (Wyatt \& Peter, 1986). Finkelhor (1979) reported from his college population that for girls there were higher sexual abuse rates on farms than for the sample as a whole.

One terrible tragedy of sexual abuse is that its not easily confined to one generation (Ney, 1988). Abuse can be transmitted across generations through children learning parenting styles from their mothers and fathers, which assures that prevalence rates will not decrease substantially unless victims are helped. 
Sorenson and Snow (1991) discovered that the majority of offenders were male and $58 \%$ of victims were abused by members of their immediate family. For $10 \%$ of the victims, the sexual activity was a single occurrence, and $88 \%$ engaged in multiple incidents ranging from several months to 7 years. In other research, $96 \%$ of offenders were male, $62 \%$ were members of the child's family, and $21 \%$ of the children had only one sexual experience (Sauzier, 1989).

Stepfathers bring with them increased risks for sexual abuse, both from themselves and because they bring into the family structure acquaintances who are not as protective toward a stepdaughter as they might be toward a biological daughter (Finkelhor, 1979). It appears that teenagers are more likely to be abused by stepfathers, whereas younger children are at risk from their.biological fathers (Sirles \& Franke, 1989). Finkelhor (1979) found that, for children who had stepmothers, the likelihood of daughters experiencing sexual abuse dropped. In the case of grandparents, who were more threatening and physically violent, most abuse is done by males, with stepgrandchildren being at greater risk (Margolin, 1992). In addition, 26 perpetrators responsible for abusing 34 grandchildren were also responsible for sexually abusing their daughters. Once the incest barrier has been broken it seems that further activity is often a matter of routine (Frude, 1982). Most incestuous relationships seem to come to an end when the girl reaches the end of adolescence.

Most studies have demonstrated a low prevalence rate of women abusers (Finkelhor, 1979; Margolin, 1992; Dube \& Hebert, 1986). In a clinical study, Faller (1987) investigated 40 women who sexually abused 63 children and found that the victims were young and two-thirds of the victims were females. Thirty-four of the women (85\%) were 
mothers to at least one of their victims, whereas $55 \%$ sexually abused only their own children. When there were also male perpetrators involved in the abuse, the researcher found that the males rather than the females usually instigated the sexual abuse. Twentythree $(36.5 \%)$ of the children were males and $40(63.5 \%)$ were females, with most of the victims being the oldest child. Nineteen $(47.5 \%)$ of the female perpetrators reported being sexually abused in their childhood.

In a retrospective chart review of 511 cases of alleged sexual abuse in children 12 and under, Dube and Herbert (1987) found that most victims (68\%) presented with histories of single assault by a known perpetrator (78\%). Although school age children were more likely to be abused by an individual outside the family or by a complete stranger. Older victims were more often involved in severe forms of sexual abuse like penetration.

Accepting a child's report of abuse by an extended family member is potentially less threatening to family stability than if the offender is the mother's partner (Sirles \& Franke, 1989). Furthermore, teenagers were less likely to be believed than younger children when they disclosed the abuse. Victims who respond to their abuse by sexually acting out, such as precocious sex play and excessive curiosity about sexual matters, may decrease the likelihood of being believed by their mothers (Sirles \& Franke, 1989).

Reliability of reporting of sexual abuse. There is currently a debate regarding the reliability and validity of reporting childhood sexual abuse, especially those cases involving repressed memories. At the moment, figures of repressed memories of childhood sexual abuse range from $18 \%$ to $59 \%$ (Loftus, 1993). Determining whether or not sexual abuse actually occurred is difficult since frequently such allegations are not 
supported by conclusive evidence (Risin \& McNamara, 1989). In addition, there are seldom third party witnesses, and admission by offenders is rare. Therefore, knowing how many times sexual abuse has not occurred is unknown.

Types of disclosure and certain aspects of sexual abuse have been shown to relate to the reliability and validity of accusations. Using the interview and survey forms of selfdisclosure, Dill, Chu, Grob, \& Eisen (1991) investigated which form was more reliable. After collecting this data on 92 consecutively women admitted for inpatient treatment, they found that the survey format elicited substantially greater frequency in reporting abuse histories (52\%) than did the intake format (35\%). When reviewing 12 domestic relations courts throughout the United States, Thoennes and Tjaden (1990) found four factors were significantly associated with the perceived validity of the abuse report: age of the victim, frequency of the alleged abuse, prior abuse/neglect reports, and the amount of time elapsing between filing for divorce and the emergence of the allegation.

\section{Negative Feelings and aspects of sexual abuse}

Several empirical studies have demonstrated that certain characteristics of sexual abuse like duration, force, and disclosure are related to how children view the abuse. In addition, it has been shown that these characteristics interact with each other. For example, the amount of force used during the abuse might be a factor influencing the duration of the abuse. Some research has discovered that increased force can lead children to disclose more quickly (Finkelhor, 1979).

Duration. Studies have shown the negative impact that duration of sexual abuse has on children's feelings. Finkelhor (1979) found that duration had a major negative impact on how children viewed the abuse, with longer length of abuse corresponding with more 
negative feelings. He also discovered that in his college sample $60 \%$ experienced a single occurrence of abuse, whereas for $40 \%$, the abuse lasted for more than a week. Research has also shown that the relationship of perpetrator to the victim can affect both duration and how the victim views the abuse. Faller (1989) noted that out of 171 cases gathered through clinical interviews, the longest duration is found in situations where the child is sexually abused by her biological father. Additionally, the length of sexual abuse might be a factor in whether children will disclose the situation to others. For example, as children get older their rates of disclosure can increase (Farrell, 1988).

Disclosure. Empirical studies have demonstrated most children never disclose. Of 142 college students who were abused as children, $63 \%$ of girls and $73 \%$ of boys did not tell anyone about the experience (Finkelhor, 1979).

Several factors can determine whether children will disclose sexual abuse. Sorensen and Snow (1991) did an archival study, drawn from the authors' caseload, that included 116 confirmed cases of child sexual abuse. They found that the disclosure process contained the four progressive variables of denial, disclosure, recant, and reaffirm. They also indicated that disclosure had two phases, tentative and active. In addition $74 \%$ were accidental disclosure, whereas adolescents were more likely to disclose purposely. They discovered that anger was a significant impetus for purposeful disclosure, exclusively in the adolescent age group. Furthermore, only $7 \%$ of the children who denied sexual abuse moved directly to active disclosure. In approximately $22 \%$ of the cases, children recanted their allegations. Of those who recanted, $92 \%$ reaffirmed their abuse allegations over time. It has been shown that whether children disclose can be related to the type of 
force used during the sexual abuse with more serious force (i.e. physical restraint) increasing the likelihood of disclosure (Sorensen \& Snow, 1991).

Farrell (1988) examined 106 proven father-daughter incest reports received by Child Protective Services (CPS) during 1985-1986. He found that 20\% were reports of nondisclosure (child did not tell), and $80 \%$ were cases of self-disclosure. He discovered that self-disclosure reports increased as the victim's age increased, until the 16 to 17 age range. Furthermore, he discovered that the more serious the abuse, the more selfdisclosure.

To investigate the sexual abuse characteristics and disclosure practices of victimized children, Sauzier (1989) evaluated 156 sexually abused children treated at the Family Crisis Program (for Sexually Abused Children) between 1980 and 1982. At follow-up, 18 months later, information was obtained from 115 of the 156 confirmed cases of sexual abuse. The researcher found that in $55 \%$ of the cases it was the abused child who disclosed. Furthermore, in 55\% of the reports, the child first told a parent or parent surrogate. Of those children who told immediately most of them had experienced the "minor" forms of abuse, ranging from exhibition to attempted contact. In addition, aggressive forms of abuse were more likely to evoke either immediate reporting by the victims $(39 \%)$ or failure to ever tell $(43 \%)$. Furthermore, children abused by a natural parent were more likely to keep it a secret, and were seen because of accidental disclosure.

Force. Finkelhor (1979) found that close to $70 \%$ of both girls' and boys' experiences involved force, which was associated with more traumatic reactions. Also, Faller (1989) indicated that paternal caretakers' methods of gaining their victim's 
cooperation were characterized by threats and force. Coercion was reported by 35 of 40 sexually abused subjects in the study by German, Habenicht and Futcher (1990).

Conte and Schumerman (1987) did a retrospective review of center records for 369 abused and 318 nonabused children who were seen at the Sexual Assault Center (SAC) in Washington, between 1983 and 1985 . They found that physical restraint of victims during abuse was associated with variation in symptoms, although the two groups differed significantly on a number of demographic variables, which qualifies their findings.

In all of these studies of abuse characteristics, instead of researching children's perceptions and feelings, checklists were filled out by either parents, social workers, or agencies. Seldom did the researchers use comparison groups, or report refusal rates. Also, they investigated only self-disclosure and studied only confirmed or referred cases of sexual abuse separately. In addition, some authors investigated archival data, which they then used to estimate levels of force and duration.

Academic ability and sexual abuse

School performance. Research has shown a mixed picture of the relationship between sexual abuse and school performance. Most research has analyzed the relationship of sexual abuse to a multitude of different aspects of people's lives, but little has looked at school performance specifically. In addition, the school-related problems that were analyzed or investigated were frequently unspecified, but included underachievement and truancy. Furthermore, most researchers focused on the immediate effects of sexual abuse by studying children. It is also of interest to know if a 
relationship can be determined between sexual abuse history and later academic functioning. This study will investigate this long term relationship to determine if differences hold up over time for a college sample. Also by obtaining measures of school performance at different time points, this study will be able to determine if there are significant trends over time for abused and nonabused women.

Many studies have demonstrated that sexual abuse has a concurrent negative relationship with children's school achievement (Conte \& Schuerman, 1987; Hibbard \& Hartman, 1992; Hubbard, 1989; Hunter, Kilstrom, \& Loda, 1985; Rao, DiClemente, Ponton, 1992; Runtz \& Briere, 1986; Rust \& Troupe, 1991; Tong, Oates, \& McDowell, 1987). Many of these studies will be addressed in more detail in the following section. For example, Hunter, Kilstrom, and Loda (1985) studied whether masked sexual abuse victims, those that presented with symptoms in the absence of admission of sexual abuse, would include more severe and long standing problems when contrasted with overt cases. They analyzed a total of 81 hospitalized children, of which 50 were referred as masked cases. They discovered that children with masked presentation of sexual abuse were more likely to have positive past histories for school problems and psychosomatic complaints than children with overt cases of sexual abuse. The authors' neglect of a control group calls into question some of their findings.

Runtz and Briere (1986) had 39 sexually abused and 111 nonabused college women complete a questionnaire to examine their childhood history of sexual abuse and adolescent behaviors. They found that sexually abused victims were more likely than their nonabused peers to have "skipped school" and "done poorly in school" in their teenage years. These findings were striking, since their sexually abused sample was 
selected from a university population, which therefore could be expected to reflect better psychological adjustment than a sexually abused sample drawn from the general population. A methodological concern with this research is that the authors totally relied on retrospective information which required women to reflect on past behavior instead of their current functioning. Also, they failed to take into account other aspects of the abuse, like relationship of perpetrator, force, and duration that could have meant that their abused sample experienced extreme sexual abuse. If their sexually abused group was comprised of victims who had experienced less abuse, they might have had fewer problems in school.

Tong, Oates, and McDowell (1987) used parental and teacher reporting and child self-reporting on various checklists, to study personality development following sexual abuse for 49 abused and 49 nonabused children. They found that the abused children had a high incidence of reduced confidence, aggressive behavior, difficulty with friendships, and school problems. But they also had a wide discrepancy between the number of clinical range profiles (scores that fall outside the normal limits) reported for the sexually abused group by parents, teachers, and children themselves. Parents reported the most clinical profiles (80\%), teachers reported slightly fewer (30\%) and children reported the fewest (13\%). The teacher's report was the most objective, because they were blind to the purpose of the study.

Rust and Troupe (1991) studied the impact on academic achievement and self-esteem of a group treatment program for 25 sexually abused victims. A group of 25 girls with similar backgrounds was used as a comparison group. The perpetrators were all family members or friends of clients' parents. School aptitude was measured with the SAT 
Form F, intermediate level. They discovered that the academic aptitude and self-concept scores of the abuse victims improved significantly after spending 6 months in group therapy. Unfortunately, the authors used only subjects who were referred for therapy, which made their conclusions generalizable only to clinical populations. In addition, they did not account for the practice effect of repeat SAT testing. Also, since subjects were attending individual therapy concurrent with group therapy, the subject's change could be attributed to either individual or group therapy, or a combination.

Although methodologically flawed, some research has shown no difference in school performance between children who were abused and their controls (Deltaglia, 1990; German, Habenicht, \& Futcher, 1990). Deltaglia (1990) collected information retrospectively from domestic court and criminal records regarding 90 cases from 1980 to 1986. However, she failed to investigate whether there was a difference in the children's past (before the abuse) and current school achievement. Also, most of the abuse was kissing and fondling, which is less extreme and may account for the lack of school problems.

Some victims of sexual abuse hide their secret by achieving in school, because education may provide a challenging añd exciting escape from home reality (German, Habenicht, \& Futcher, 1990). German, Habenicht and Futcher (1990) studied 40 female adolescent incest victims, referred by their therapists, and found that they showed more confidence about physical and intellectual and school status than other aspects of selfconcept. However, these children were in individual therapy, which might account for their higher self-concept. In addition, with the inclusion of a control group they may have discovered that sexually abused children have more school problems than controls. 
In a paper presentation at American Psychological Association (APA), Lusk, Waterman, Kelly, McCord, and Oliveri (1993) investigated school-related differences in 15 ritually (RA) and 15 non-ritually (NRA) sexually abused children. They found that when intelligence was controlled for, there were no significant differences in achievement between groups. Furthermore, RA children did not have more external locus of control than NRA children in the cognitive domain, although they observed that NRA children showed more positive school-related attitudes. Some of the methodological issues with this research are that the groups were small in sample size and not demographically comparable, nor was a control group recruited.

The above illustrates a variety of methodological issues that make interpretation of childhood sexual abuse research difficult. The problem with these school studies is that most fail to report how school problems were defined. Also, none mentioned the relationships of disclosure, parental support, therapy, or how children dealt with sexual abuse. Studies involving children need to also use teacher assessment, reviews of school records or classroom observation. No study investigated the wide spectrum of different victims, from those needing hospitalization to those functioning normally, but instead all focused on one side of the continuum. Many researchers used new scales, but declined to report any information on how the scales held up. Instead, they tended to write about individual items, which statistically contain more error. Some of the authors had parents fill out measures that alluded to school problems, which were subject to the parents' perceptions.

While an abundance of research has documented the negative relationship between sexual abuse and school performance within a few years of the abuse, none have looked 
at the relationship of childhood sexual abuse to school perception and performance in later years. In addition, the participant's perceptions regarding their school ability needs to be investigated in order to give a more rounded picture of victims. For instance, this study will use different school measures and investigate learning styles to obtain a clearer picture of the woman's overall school experience past and present.

School perception. No study has investigated the interaction of sexual abuse and how students perceive their scholastic abilities, although one retrospective study asked women to reflect on their child or adolescent school activities to investigate school problems (Runtz \& Briere, 1986). Another facet that has not been studied is the relationship between sexual abuse and children's learning ability.

\section{Learning and sexual abuse}

The few studies that have investigated learning have focused on learning difficulties, or behavior problems (Friedrich, Urquiza, \& Beilke, 1986; Friedrich, William, Grambsch, Damon, Hewitt, Koverola, et al. 1992). No research has studied students' learning styles in conjunction with sexual abuse.

Attitude. General attitudes and motivation can affect a student's success in school

-. and in performing tasks related to school success." But no researchers of childhood sexual abuse have looked at the students' attitudes regarding school.

Motivation. Another neglected area is the degree to which students accept responsibility for studying and for their performance, which is reflected in the everyday behavior they exhibit related to school and school tasks. It would appear that sexual abuse victims usually feel a lack of control over their lives, so they would not be inclined to take responsibility for their school performance. 
Anxiety. While the relationship between anxiety and sexual abuse has been investigated, school anxiety has not been a focus of any research dealing with sexual abuse. Also the negative thoughts about one's abilities, intelligence, future, interactions with others, or likelihood of success that can divert a student's attention away from the task at hand have not been considered (Weinstein, Palmer, \& Schulte, 1987). If students are tense, anxious, or fearful about studying or performing in academic situations, this could divert their attention away from the academic task and inward to self-criticism or irrational fears. Sexual abuse victims have a tendency to be self-critical and this could make them tense or anxious in school situations.

Concentration. Lust et al. (1993) found that ritually abused children had more problems with attention and concentration than non-ritually abused children. Students who are able to concentrate can focus their attention on school-related activities, such as studying and listening in class, rather than on distracting thoughts, emotions, feelings, or situations (Weinstein, Palmer, \& Schulte, 1987). For those students who have been sexually abused there are a variety of issues that can distract them from learning in school.

\section{Adult Psychosocial Functioning}

Most research indicates that childhood sexual abuse is associated with multiple short and long-term psychological difficulties. Tsai, Feldman-Summers, and Edgar (1979) found that victims having more problems in living, as assessed by the Minnesota Multiphasic Personality Inventory, were older at the last sexual abuse incident, were abused for a longer duration, were more frequently abused, and had intercourse attempted more often. These correlations occurred in nonclinical and clinical samples 
and were present in both males and females. Elliott and Briere (1992) found in a national survey for the Trauma Symptom Checklist-40 (TSC-40) that women who reported sexual abuse histories scored significantly higher than controls on each of the six subscales (Dissociation, Depression, Anxiety, Sleep Disturbance, Sexual Problems, Sexual Abuse Trauma Index) and the total TSC-40 score.

Dissociation. Dissociation can serve to block painful events from awareness and is adaptive because it allows people to go about their lives as if nothing traumatic has happened. For victims of sexual abuse certain events, especially those that involve force can make life difficult, but through the use of dissociation life can be managed.

However, people who use dissociation too much can become too fragmented to function. Some empirical evidence suggests that dissociative symptoms significantly discriminate between sexually abused and nonabused adults, and that certain aspects of the abuse (e.g., intercourse) are associated with elevated levels of dissociation in these subjects (Briere, \& Runtz, 1986; Elliott \& Briere, 1992; Malinosky-Rummell, \& Hoier, 1991).

Sandberg and Lynn (1992) compared 33 female college students who scored in the upper 15\% on the Dissociative Experiences Scale (DES) with 33 female students who scored below the mean on the DES. These two groups were also compared on college adjustment, and child and adolescent maltreatment. The higher DES subjects reported more psychopathology, poorer college adjustment, and greater extent of psychological, physical, and sexual maltreatment. This study suggested that a positive relationship exists between dissociative experiences in nonclinical populations and adolescent sexual victimization where threats or actual physical force was used. 
Anxiety. Many studies have demonstrated the negative relationship between sexual abuse and a victim's anxiety (Bushnell, Wells, \& Oakley-Browne, 1992; Cohen, \& Mannarino, 1988; Gidycz, \& Koss, 1989), although none of these researchers have looked at anxiety alone. By contrast, Grayston, de Luca, and Boyes (1992) found that levels of anxiety and loneliness did not differ between the sexually abused and nonabused groups. A fault of this latter conclusion is that levels of abuse were not assessed, so their sexually abused sample could have been from the less severe end of the continuum.

Gidycz and Koss (1989) studied the differences on anxiety, depression, and behavioral deviancy between a nonclinical sample of 67 sexually victimized and nonvictimized high school girls. The sexually abused girls scored significantly higher than nonabused girls on the standardized anxiety and depression measures. They also found that the extent of victimization contributed significantly to the prediction of both the depression and anxiety scores.

Sleep Disturbance. Sleep problems can be one symptom of sexual abuse victimization (Rao, DiClemente, \& Ponton, 1992), but no research has looked at this problem specifically. Hibbard and Hartman (1992) reported on the behavior problems of 81 sexual abuse victims and 90 nonabused children. They found that the alleged sexually abused children had more trouble sleeping than the comparison group. The prevalence of sleep problems among the sexually abused group was $23 \%$, whereas Sauzier (1989) found that, after an 18 month follow-up, sleep problems decreased for sexually abused children. In addition, Goldston, Turnquist, and Knutson (1989) did a chart review of 70 sexually abused and 43 nonabused girls looking at behavioral problems. They discovered that in this clinic population, the younger sexually abused girls (ages 2-11) had 
significantly more sleep disturbances and sexual behaviors. Unfortunately, in most studies sleep problems are just one of many symptoms the authors are investigating; therefore, there is no really strong independent measure of it. Also, interaction between sleep disturbance and other symptoms like dissociation and anxiety are seldom discussed.

\section{Social Support}

Another aspect of how children deal with sexual abuse is dependent on their social support networks, especially the support of their mothers. A victim's supportive relationships with an adult or sibling is one factor associated with variations in symptoms like sleep disorders, anxiety attacks, and low self-esteem. (Conte \& Schuerman, 1987). The severity of the long-term relationships of sexual abuse appears to be mediated by the support received from the children's nonabusive parent, family and friends (Conte \& Schuerman, 1987). When children disclose sexual abuse to their mothers, who do not believe them, it can serve to invalidate their reality and have an extremely negative effect. Children who are not supported are at risk for suicide and other serious problems (Sirles \& Franke, 1989)

There is only one reported study that specifically addressed why a mother believes or disbelieves reported abuse. A clinical study of 193 mothers by Sirles and Franke (1989) reported that, whether mothers believed their child regarding intrafamily abuse was dependent on many factors. The vast majority of mothers believed their child (78\%), whereas only $22 \%$ did not believe their child. Mothers were most likely to believe reported abuse if the offender was an extended family member instead of the father. However, a mother was less likely to accept the abuse disclosure when the abuse involved genital-genital contact or occurred when the mother was at home. Practically all 
the mothers of preschool-age victims believed their child, with a dramatic decrease occurring as the children reached adolescence. When the child was physically abused as well as sexually abused by the offender, mothers tended to think that children fabricated the sexual aspect of the abuse to get revenge on the offender for the physical abuse.

Hubbard (1989) interviewed 11 mothers whose daughters had allegedly been sexually abused by their father or father figure to evaluate the mother's perceptions of the sexual abuse. They found that these mothers were unable to consistently protect their daughters or reconstruct their family after the incest was disclosed. In addition, in 10 of the 11 families, the daughters were either never believed or inconsistently believed by their mothers. This lack of consistent support could have detrimental effects on the daughters.

Rao, DiClemente and Ponton (1992) did a retrospective chart review study of a sexual abuse clinic, which compared Asian youths with African American, Caucasian, and Hispanic victims. They found that Asians had less supportive primary caretakers than non-Asians. In addition, the Asian group was most likely to be abused by a male relative. In this study the Asian group represented many diverse Asian cultures, languages and degrees of Westernization, which limits the generlizability of the results of the study.

None of these studies dealt with how children perceived the support they obtained from their mothers, but rather focused on abuse characteristics, or how supportive mothers' were through their actions. Most information about social support was reported by mothers of children who have been sexually abused. In addition, there were no comparison groups to investigate how mother's general support would have compared. 


\section{General Study Goals}

The present study extended previous work in this area by comparing women with abuse histories to women without abuse histories on a variety of school and living problems. Problems in school were conceptualized as including school aptitude, achievement, perception, and learning styles. Problems in living included a number of psychosocial variables such as anxiety, dissociation, sleep disturbance, and social support.

This study expanded on previous studies by examining a wider range of variables. Uncharted ground was explored by examining the relationship between learning styles, school perception, social support, and sexual abuse. Furthermore, this study investigated whether there was a long term relationship between childhood sexual abuse and later school functioning. A number of hypotheses follow.

\section{Hypotheses}

\section{Negative Feeling Variables}

1. For women who report abuse, there will be a positive relationship between duration and negative feelings regarding the abuse, as measured by the Finkelhor Inventory.

2. For women who report abuse, there will be a positive relationship between force and negative feelings regarding the abuse, as measured by the Finkelhor Inventory.

3. For women who report abuse, there will be a positive relationship between disclosure and negative feelings regarding the abuse, as measured by the Finkelhor Inventory. 


\section{School Variables}

4. Abused women will report less belief in their scholastic ability, as measured by the Self-Perception Profile, than the nonabused women.

5. Abused women will report less belief in their intellectual ability, as measured by the Self-Perception Profile, than the nonabused women.

6. Abused women will report less academic aptitude, as measured by the SAT score, than the nonabused women.

7. Abused women will report less academic performance, as measured by the GPA score, than the nonabused women.

\section{Learning Styles Variables}

8. Abused women will report less attitude, as measured by the LASSIE, than the nonabused women.

9. Abused women will report less motivation, as measured by the LASSIE, than the nonabused women.

10. Abused women will report more learning anxiety, as measured by the LASSIE, than the nonabused women.

11. Abused women will report lessconcentration, as measured by the LASSIE, than the nonabused women.

\section{Psychosocial Variables}

12. Abused women will report more pathological symptoms, as measured by the TSC-33, than the nonabused women.

13. Abused women will report more dissociation, as measured by the TSC-33, than the nonabused women. 
14. Abused women will report more anxiety, as measured by the TSC-33, than the nonabused women.

15. Abused women will report more sleep disturbance, as measured by the TSC-33, than the nonabused women.

\section{Social Support Variable}

16. Abused Women will report less emotional social support, as measured by the SS-B, than the nonabused women.

17. Abused Women will report less financial social support, as measured by the SS$\mathrm{B}$, than the nonabused women.

18. Abused Women will report less advice/guidance social support, as measured by the SS-B, than the nonabused women. 


\section{Method}

\section{Participants}

Data were collected in the fall of 1993 and the spring of 1994 from undergraduate students attending the University of Rhode Island. Recruitment from undergraduate students targeted women attending general psychology courses. Based on any positive endorsement of any item of the Finkelhor sexual abuse inventory, 50 women were put into the sexually abused group. Based on no positive endorsement of any item of the Finkelhor sexual abuse inventory, 50 women were designated as the nonabused group. Participants were required to be 18 years of age or older. All responses were kept confidential.

For students recruited from the introductory psychology courses, the instructors informed the class members that they could earn credit by enrolling in an experiment. Students signed up to participate in the study on posted rosters on a bulletin board outside the office of the psychology department. Each roster listed the name and principal investigator of the study, location, date, and time of the experiment, and the number of credits the student would receive. The rosters stated that in order to participate, subjects must be 18 years of age and have some form of identification present at the time of the session.

\section{$\underline{\text { Measures }}$}

A questionnaire of 216 items tapping women's school achievement and perception, current social support, history of sexual abuse, and psychosocial characteristics was administered. A subset of these questions was used in this study. For a list of these items, see Appendix B. 
Demographic information. Respondents were asked to indicate their age, year in college, race, income, and current relationship.

Therapy variables. Respondents were asked to indicate whether they are currently in counseling, for how long, and how often.

Family loss variables. Respondents were asked to indicate the parents' current marital status. In addition, respondents were asked to indicate whether any of the following of their relatives have died: parental grandmother, parental grandfather, maternal grandmother, maternal grandfather, mother, father, sisters, and brothers, as well as how old they were when that person died.

Childhood Sexual Abuse. In order to assess characteristics of their sexual abuse history, 26 items were adapted from Finkelhor's Sexual Abuse Inventory (1979). For those who were abused before the age of 12 by someone 5 or more years older, items to assess aspects of the abuse included: duration, frequency, disclosure, how old they were when they disclosed, force, feelings about abuse past and current, age of victim, age of perpetrator, sex of perpetrator, relationship between victim and perpetrator; and type of abuse, which ranged from no contact to intercourse (see Appendix B). For those who were abused over the age of 12 by someone 5 or more years older, items to assess aspects of the abuse included: duration, frequency, disclosure, how old they were when they disclosed, force, feelings about abuse past and current, age of victim, age of perpetrator, sex of perpetrator, relationship between victim and perpetrator, and type of abuse, which ranged from no contact to intercourse (see Appendix B).

The Finkelhor sexual abuse inventory abuse was used rather than just one global sexual abuse question in order to more clearly measure components of the sexual abuse. 
Wyatt and Peters (1986) stated that the more specific questions you ask participants, the clearer their overall picture of childhood sexual abuse will become. In addition, participants did not have to indicate whether they had been abused because this could be determined later by the way they responded to certain questions.

School Aptitude. The Scholastic Achievement Test (SAT) (College Entrance Examination Board, 1976) scores were obtained from the students' records to determine their school aptitude. In addition, a self-report of their SAT scores was obtained. This test is required for all students applying to college and has good reliability and validity. The reliability coefficient estimated for specific scales range from .83 to .91 (Donlon, 1984). The validity estimated for specific percentiles of the test range from .20 to .40 for 10th percentile and .50 to .70 for the 90 th percentile.

School Performance. High school grade point average (GPA) was obtained from the students' records to determine their high school ability. This measure is required for all students applying to college and has good reliability and validity. In addition, a selfreport of their average grade for grades 9 th through 12th was obtained. The correlation coefficients between self-reporting and transcript data range from .53 to .89 (Birnbaum, 1972; Sawyer, Laing, \& Houston, 1989; Goldman, Flake, \& Matheson, 1990). The correlation between SAT scores and self report of high school grades is estimated to be .46 (Stricker, 1991).

School Perception. The Self-Perception Profile for College Students (Neemann \& Harter, 1986) is a self report measure for undergraduate students with a 54-item Likert type scale. Responses were coded on a four point scale with higher scores indicating better school perception. The two subscales of intellectual ability and scholastic 
competence, which were the only two subscales used, had four items each. First the subject decided which one of the two parts of each statement best described her; then she went to that side of the statement and checked whether that was just "sort of true" for her or "really true" for her. The internal consistency estimated for specific scales ranged from .76 to .92 . Factor analytic techniques confirmed the proposed delineation of subscales.

Learning. The Learning and Study Strategies Inventory (LASSIE: Weinstein, Palmer, \& Schulte, 1987) is a copyrighted 77-item Likert type scale. Responses were made on a five point scale $(1=$ "Not at all typical of me", to $5=$ "Very much typical of me") with higher scores indicating better learning styles. Eight items each tapped the four factors of attitude, motivation, anxiety, and concentration. For the specific scales, the coefficient alpha ranges from .68 to .86 and the test-retest correlation coefficient ranges from .72 to .85 .

\section{Psychosocial Measures}

Symptomatology. The Trauma Symptom Checklist (TSC-33: Briere \& Runtz, 1987) is a 33-item Likert type scale. Responses were made on a five point scale $(1=$ "Never", to $5=$ "Very often") with higher scores indicating greater symptomatology. This scale has been widely used with college and clinical samples. Six items each tapped the two factors of dissociation and PSAT-h (Post Sexual-Abuse Trauma hypothesized); nine items each tapped the two factors of depression and anxiety; and four items were associated with the sleep disturbance factor. Only the subscales measuring dissociation, anxiety, and sleep disturbance were used. The internal consistency estimated for specific scales ranged from .66 to .75 . 
Social Support. The Social Support Scale (SS-B: Vaux \& Schuder, 1987) is a 90item Likert type scale. Responses were made on a five point scale $(1=$ "No one would dò this", to 5 = "Most family/friends would do this") for family support and then again for friend support with higher scores indicating greater support. Eight items each tapped the two factors of financial assistance and practical assistance; six items were associated with the socializing factor; ten items were associated with the emotional support; and twelve items were associated with the advice/guidance factor. Only the subscales for emotional support, financial assistance, and advice/guidance were used. The lowest internal consistency estimated for specific scales was .80 . The content validity estimated for specific scales ranged from .82 to .92 .

\section{Procedure}

Participants completed questionnaires in a lecture hall or classroom in a group ranging in size from 5 to 100 women. Before the arrival of students, specific instructions concerning the computer response sheets, such as how to enter the responses on both the sheets and questionnaires were written on the board. Once the students arrived, they were instructed to sit with one empty seat between each person to insure privacy. The researcher then explained the study and went over the instructions for filling out the questionnaire. Because of the sensitive materials in the questionnaires which could evoke painful feelings, the students were informed of the phone numbers on the instruction sheet to call in the event they felt upset (see appendix A). They were all then told to tear off and keep this portion, so that those with sexual abuse issues were not singled out. Once the study was explained, students were asked to read and if they wished, sign two consent forms. The first was a consent to participate in the study. The second was a 
consent to release their SAT scores and GPA. At this point, any student unwilling to participate was given the opportunity to leave. Subjects were asked not to put any identifying information on either the survey or the response sheet, and the participant number written at the top of each form was explained as a confidential cross-check for keeping together all forms from an individual. Participants were assigned an identification number which was used to code their questionnaires. The principal investigator retained a list equating their names and ID numbers which was kept in a locked file cabinet separate from their questionnaires. After obtaining their SAT scores and GPA, the researcher used this list to transfer their SAT scores and GPA to a sheet coded with their ID numbers, and destroyed information linking their names to their SAT scores and GPA. After the students finished, they put the completed surveys face down in a stack on a table that was located several feet from the researcher. On their way out of the room, they were thanked for their participation and reminded that any questions should be directed to Patricia Lee in the psychology department. Her name and campus address were on the informed consent form, which students were given for their records. 
Results

\section{Background Information}

In the sample of 333 women, 50 or approximately $15 \%$ reported experiencing childhood sexual abuse. This is similar to the reports in the literature regarding the prevalence of childhood sexual abuse in college samples. Because considerably fewer participants reported a history of childhood sexual abuse, a comparison group of nonabused participants was randomly selected from the entire group not reporting abuse using the random sample generator function in SPSS. The function was seeded so that the random sample would include approximately 50 of the nonabused group. Thus, analyses of group differences were conducted on a sample which was composed of 50 women who reported a history of childhood sexual abuse and a randomly selected sample of 50 women who did not report a history of abuse

The specific characteristics of each group are presented in Table 1. The mean age was 20 years for the abused groups and 19 for the non-abused group. Most participants were in their freshman year: $72 \%$ in both the abused and nonabused groups. Ethnic and cultural diversity were low, with $76 \%$ of the abused group and $88 \%$ of the nonabused group being Caucasian. When reporting their current living arrangement, participants mostly classified themselves as single (48\% in the abused group and $62 \%$ in the nonabused group). Participants also came from predominately middle class homes with their gross family income being around $\$ 35,000$ and over: $49 \%$ in the abused group; $67.3 \%$ in the nonabused group. The majority of participants were not in counseling, $88 \%$ in the abused group and $100 \%$ in the nonabused group. Overwhelmingly, participants' parents were married: $70.2 \%$ in the abused group; $81.6 \%$ in the nonabused 
group. Furthermore, Table 1 includes the specifics regarding the loss variables, which show that generally the participants' family members currently are living.

\section{Sexual Abuse Characteristics}

In Table 2, the specifics regarding the sexual abuse are presented, separated by whether the abuse occurred before the age of 12 or after the age of 12 years old. The victim's mean age was 7.59 years, for the under 12 years abused group and 14.44 years for the 12 and over abused group. The abuser's mean age was 19.24 years, for the under 12 years abused group and 35.56 years for the 12 and over abused group. Most abusers were male: $90.7 \%$ in the under 12 group; $100 \%$ in the 12 and over groups. Generally the relationship of the victim to the abuser was that of a friend; $29.3 \%$ for the under 12 years abused group and $37.5 \%$ for the 12 and over abused group. Regarding the characteristics of the abuse, there were high percentages of both the contact and noncontact type.: For $43.6 \%$ in the under 12 years abused group and $56.3 \%$ in the 12 and over abused group force was not used. When reporting whether the abuser was drinking, $87.5 \%$ in the under 12 years abused group and $43.8 \%$ in the 12 and over abused group stated no. Many of the participants also reported that the abuse only occurred once (52.4\%, for the under 12 years abuised group and $50.0 \%$ for the 12 and over abused group). The majority of participants expressed that fear was their predominant reaction at the time of the abuse: $70 \%$ in the under 12 years abused group; $56.3 \%$ in the 12 and over abused group. Generally, women reported disclosing the abuse to at least one person: $36.4 \%$ in the under 12 years abused group; $37.5 \%$ in the 12 and over abused group. The majority of the participants expressed feeling negative about the 
abuse, $65.1 \%$ for the under 12 years abused group and $37.5 \%$ for the 12 and over abused group.

\section{Comparison of Abused and Non-Abused Regarding Demographics}

To investigate group differences on demographic variables, a Multivariate Analysis of Variance (MANOVA) was done. A MANOVA performed on demographics, age, grade, income, ethnicity, parental status, and current living arrangements, revealed significant differences between the two groups $[\mathrm{E}(6,87)=2.29, \mathfrak{p}<.05]$. Wilks' Lambda $=.86$, indicating that $14 \%$ of the variance in these demographic measures can be accounted for by knowing their sexual abuse status. Follow-up univariate F-tests showed no significant differences between groups regarding grade, ethnicity, parental status, and relationship. However, significant differences between the groups revealed that the abused women were older $[\underline{F}(1,98)=4.02, \mathrm{p}<.05]$, and had lower incomes $[\underline{E}(1,96)$ $=5.39, \mathrm{p}<.02]$. In addition, to investigate whether age and income should be used as covariates when performing the other MANOVAs, the correlations between age, income, and the other dependent measures were run. It was found that only the SAT combined measure was correlated with age and income at a value slightly greater than 0.3 .

\section{Outcomes of Loss Variables}

A MANOVA performed on the loss measures, status of paternal grandmother, paternal grandfather, maternal grandmother, maternal grandfather, mother, father, sister, and brother, showed no significant differences between the two groups. To determine the extent that these loss measures were related to the school variables, a Multiple Regression was done. None of the loss variables significantly predicted any of the school measures. 


\section{Outcomes of Dependent Variables}

A series of MANOVAs and a Multiple Regression were done to statistically test the

- stated hypotheses. Dependent variables were grouped by categories of behaviors (i.e., school variables, learning styles, symptomatology, and social support) in these analyses. The means and standard deviations of the dependent variables for the abused and nonabused groups are provided in Table 3.

Regression Analysis of Characteristics of Sexual Abuse as Predictors of Feelings Regarding the Abuse

Hypothesis I-III. In order to test the hypotheses that force, duration, or disclosure would influence how women who were abused feel about their abuse, a multiple regression was conducted. Predicting the feelings regarding the sexual abuse by characteristics of the abuse (force, duration, and whether the woman ever disclosed the abuse to anyone) was not significant.

\section{Comparison of Abused and Non-abused for School Variables}

Hypothesis IV-VII. A MANOVA was conducted to compare the sexually abused (SA) and non-sexually abused (NSA) groups on measures of intellectual ability, scholastic competence, an averaged self-repofted high school GPA, and SÁT combined scores found no significant differences. A Multivariate Analysis of Covariance (MANCOVA) that used age and income as covariates was conducted on the same dependent measures. This revealed a trend toward a significant difference between the SA and NSA groups. An ANCOVA that used age as a covariate found no significant differences between the SA and NSA groups on the measure of SAT combined scores. However an Analysis of Covariance (ANCOVA) that held income constant revealed a significant difference 
between the two groups on the measure of SAT combined scores $F(1,82)=5.55$, p < .05 .

A 2 by 4 mixed factorial ANOVA with repeated measures as the second variable was performed. The first between subjects variable was group (SA vs. NSA). The second repeated measure was high school GPA (self-reported high school GPA: 9th grade, 10 th grade, 11 th grade, and 12 th grade). This was found to be statistically significant for the interaction $\mathrm{F}(3,291)=6.62, \mathrm{p}<.000$, whereas there were no significant main effects. Follow-up univariate F-tests conducted to investigate group differences on high school GPA at the different time points were significant, demonstrating that the SA group had significantly higher 9th grade GPAs $F(1,98)=$ $10.07, \mathrm{p}<.002]$ than the NSA group. However no significant group differences were found regarding 10th grade GPAs, 11th grade GPAs, or 12th grade GPAs. This relationship was also graphed for the SA and NSA groups (see Figure 1) and for women who were abused when they were 7 and under, 8 and over, and a comparable NSA subgroup (see Figure 2).

A trend analysis was done to compare the mean performance for high school GPA for the different grade levels. For the NSA group only the linear trend was found to be significant $F_{\text {linear }}(1,49)=18.99, p<.0001$, whereas for the SA group only the quadratic trend was significant $F_{\text {quadratic }}(1,48)-8.69, p<.0049$. The variability for the NSA group as indexed by the $\mathrm{R}_{\text {linear }}^{2}$ was .98 , whereas the variability for the SA group as indexed by the $\mathrm{R}_{\text {quadratic }}^{2}$ was .59 . 


\section{Comparison of Abused and Non-abused for Learning Styles}

Hypotheses VIII-XI A MANOVA conducted to compare the SA and NSA groups on the learning style measures of motivation, anxiety, concentration, and attitude found no significant differences.

\section{Comparison of Abused and Non-abused for Psychosocial Variables}

Hypotheses XII-XV A MANOVA comparing the two groups on psychosocial variables did reveal significant differences between the groups $[\mathrm{E}(3,94)=2.66, \mathrm{p}<$ .05 ]. Wilks' Lambda $=.92$, indicating that $8 \%$ of the variance in the three dependent variables; (dissociation, anxiety, and sleep disturbance) can be accounted for by sexual abuse status. Follow-up univariate F-tests showed that women reporting childhood sexual abuse had greater dissociation $[\mathrm{F}(1,97)=6.97, \mathrm{p}<.01]$, anxiety $[\mathrm{F}(1,96)=4.99, \mathrm{p}<$ $.03]$, and sleep disturbances $[\mathrm{E}(1,97)=4.74, \mathrm{p}<.03]$ than women who do not report a history of childhood sexual abuse.

\section{Comparison of Abused and Non-abused for Social Support}

Hypotheses XVI- XVIII Reported emotional, advice/guidance, and financial support of participants reporting childhood sexual abuse were compared with those of participants not reporting abuse: A MANOVA performed on a measure of social support found significant differences between the two groups $[\mathrm{E}(3,89)=2.66, \mathrm{p}<.05]$. Wilks' Lambda $=.92$, indicating that $8 \%$ of the variance in the measures of social support can be accounted for by a history of childhood sexual abuse. Follow-up univariate F-tests revealed that women reporting childhood sexual abuse report less advice/guidance support $[\mathrm{E}(1,96)=6.67, \mathrm{p}<.01]$, and financial support $[\mathrm{E}(1,92)=4.85, \mathrm{p}<.03]$, 
than nonabused women. However there was no significant group difference regarding emotional support.

Intercorrelations of Subscales

Correlations between the dependent subscales and the independent variable group were calculated for the entire sample. This correlation matrix is presented in Table 5. In addition, correlations between the dependent subscales and the independent variable group were calculated for the subsample of 100 women. This correlation matrix is presented in Table 6. 


\section{Discussion}

The purpose of this study was to investigate the differences in academic functioning variables, learning styles, psychosocal variables, and social support between college women who indicated a history of childhood sexual abuse and a comparison group of college women who did not report childhood sexual abuse. A significant interaction between experience of sexual abuse and year in high school was found for high school GPA, indicating that women who were sexually abuse as children had higher GPA's at 9th grade. In addition, GPA was found to follow different significant trends for each group. There were no significant differences discovered in learning styles and school perception between the two groups. In all other areas investigated, sexually abused women reported significantly more problems in functioning. For a summary of the outcomes of the study see Table 4 .

Significant differences were discovered between women who had a history of childhood sexual abuse and nonabused women regarding demographics (i.e., age, and income). Women who were sexually abused as children had lower incomes and were generally older when compared to women who were not sexually abused as children. Previous research has indicated that women with abusive histories are less inclined to attend college right out of high school. Therefore, the older participants might be women who first had to deal with their sexually abusive past before they were capable of returning to school. There were no significant differences between women with childhood sexual abusive pasts and nonabused women regarding grade, ethnicity, parental status, and relationship status. 
In the area of family loss there were no significant differences between women who had been abused as children and nonabused women concerning status of paternal grandmother, paternal grandfather, maternal grandmother, maternal grandfather, mother, father, sister, or brother.

Contrary to other research (Finkelhor, 1979) predicting participants' feelings regarding the childhood sexual abuse using the characteristics of the abuse (force, duration, and whether the woman ever disclosed the abuse), these factors were not shown to be significant in this sample. This finding may be due to the fact that most of the sexual abuse occurred only once, which is a relatively short time compared to the time frames that previous research has examined (Briere \& Runtz, 1988). This may also be a result of the fact that, in general, more women had negative feelings concerning the abuse regardless of whether force was used, duration of abuse, or whether they had ever disclosed the abuse. Another thing to consider is that although many women told someone about the abuse, they were not queried as to whether that person believed them, which might play a part in how they felt about the abuse. It could be that social support mediated the relationship between childhood sexual abuse and the characteristics of the abuse. Therefore, one form of social support may have been that these women were believed when they disclosed the sexual abuse, which could have minimized their selfblame.

Sexual abuse appears to have a complex relationship with school functioning. Women who reported a history of childhood sexual abuse did not demonstrate significant differences compared to nonabused women on measures of intellectual ability, scholastic competence, averaged self-reported high school GPA, and SAT combined scores. An 
extremely interesting finding in the area of school performance involved high school grade point average. There were significant differences on the GPA variables (selfreported high school GPA: 9th grade, 10th grade, 11th grade, and 12th grade) between the childhood sexually abused women and the non-abused women. Nevertheless, contrary to what was hypothesized, women that were sexually abused reported significantly higher 9 th grade GPA. No other significant group differences regarding 10 th grade GPA, 11th grade GPAs, and 12th grade GPAs were found. It has been suggested that women who are sexually abused in childhood will achieve academically in an effort to either over compensate or exhibit control in at least one area of their lives (German, Habenicht, \& Futcher, 1990). Another interesting facet of these school measures was that women who experienced childhood sexual abuse had higher GPA's until 11th grade when women without a history of sexual abuse GPA's became higher, although not significantly higher (See Figure 1). Although not addressed specifically, this pattern may be accounted for by the sexually abused women's need to control some aspects of their lives, which they may have done successfully for a time. However, during 11th and 12th grades, dating and relationships usually occur. These new relationships may bring up issues regarding the sexual abuse which in turn interferes with their academic achievement.

In the beginning, high school GPA was related to childhood sexual abuse, but as time went on, there were no significant difference between the two groups. There appeared to be two different trends for the SA and NSA groups. The NSA group proceeded through high school in a linear fashion in which their high school GPA got better with time. A potential explanation for the trend in the NSA group is that starting a new school is 
difficult, but over time they adapt. Conversely, the SA group starts high school excelling academically, because school has always been an area where they feel in control. However, when relationship issues, which may trigger their sexual abuse issues, arise in 10th and 11 th grades, they may suffer academically. Apparently though, by 12 th grade they appear to recover, because these are women who have made it to college. It might be hypothesized that a different trend would appear for a more clinical population of women, who do not make it to college right away and may instead drop out of high school. For the NSA group, each year brings better adjustment as they start to prepare for college. However, the SA group started out high school with a significantly higher GPA, which dipped and then recovered. This could be attributed to the fact that the women who were not sexually abused could have suffered other types of abuse (i.e., physical or neglect) which are also related to school problems (Egeland, Sroufe, \& Erickson, 1983; Perry, Doran, \& Wells, 1983; Reyome, 1993). In addition, these nonabused women may have experienced other types of victimization like rape or battering, which may have had an equalizing or increased impact regarding these school measures in relation to past childhood sexual abuse.

The fact that this was a college sample may indicate that child sexual abuse does not relate to school functioning in the long term. Most of the school measures investigated the participants' current functioning or perceptions. The results may have been different if there had been questions regarding school functioning closer to the time the sexual abuse occurred. Research that has found relationships between sexual abuse and school problems either fail to specify the definition of school problems or sampled children 
(Plante, Goldfarb, \& Wadley, 1993). It may be that time since the abuse occurred had mediated the relationship between the abuse and school functioning.

For instance, Einbender and Friedrich (1989) studied the psychological functioning and behavior of 46 sexually abused girls (6-14) and 46 nonabused girls matched on demographics. They found that the sexually abused children had lower cognitive abilities and school achievement. However, these were referred girls who were dealing with the various disclosure issues. For example, 11 of the sexually abused girls were in foster homes.

Furthermore, nonabused women could have had school problems or learning disabilities that may have affected how they responded to the various school measures. Bosco and Robin, (1980) studied junior high school students and found a rate of $3 \%$ (both sexes) had attention deficit hyperactivity disorder (ADHD). Gittelman, Mannuzza, Shenker, and Bonagura, (1985) also discovered that ADHD persisted to early adulthood in $31 \%$ of a group that was originally diagnosed in preadolescence. Another study demonstrated a prevalence rate of Specific Learning Disability (SLD) that ranged from $3 \%$ to $7 \%$ of school aged children, of which $20 \%$ were attributed to Attention Deficit Disorder (ADD) (Silver, 1986): Correspondingly, having a history of past school problems in turn could be negatively related to their perceptions of themselves as academically competent.

The specific hypotheses concerning the new area of learning styles was not supported. There were no significant differences found between women who had a history of childhood sexual abuse and nonabused women concerning motivation, anxiety, concentration, and attitude. This again might be attributed to the fact that physical abuse, 
neglect, and victimization were not queried, which may have made the groups more similar than they should have been.

In keeping with prior research, the hypotheses regarding the relationship between childhood sexual abuse and psychosocial functioning were greatly supported in this study (Finkelhor, 1979; Briere \& Runtz, 1988). Comparing the two groups on psychosocial variables revealed significant differences between women who reported a history of childhood sexual abuse and women who did not report a history of sexual abuse. Women who indicated a history of childhood sexual abuse had higher anxiety, dissociation, and sleep disturbances than women who do not report a history of childhood sexual abuse.

Briere and Runtz (1988) investigated the incidence and long-term effect of sexual abuse in 278 nonclinical college women. They showed that on the Hopkins Symptom Checklist, sexually abused women reported higher levels of dissociation, somatization, anxiety, and depression than nonabused women. When children are sexually abused, there are instances when the event is so traumatic for them that they have to disengage or dissociate from the situation in order to cope.

There were significant differences between women with a history of childhood sexual abuse and women without a history of childhood sexual abuse concerning social support. Women who indicated childhood sexual abuse reported less advice/guidance, and financial support than women who did not indicate abuse. This is an important finding because researchers have indicated the importance of social support as a mediating variable that could be used in structural equation modeling (Conte \& Schuerman, 1987). However there was no significant difference between abused women and non-abused women regarding emotional support. It could be that having similar emotional support 
enables the SA group to continue on to college, where maybe a more clinical population would show less emotional support.

Wyatt and Mickey (1987) examined the support of nonabusing parents as it affected adjustment to childhood abuse and women's attitudes toward men. They found that negative attitude toward men tended not to be related to the severity of the child abuse experience if nonabusing parents and others supported victims upon disclosure of abuse. Here is another instance where social support during the disclosure process can help victims regain control of their lives and lessen the lasting effect of child sexual abuse.

Abused women had higher 9th grade GPAs although they received less support and were more symptomatic than non-abused women. In addition, as dissociation increased, high school grade point average for grades 9th through 12th decreased. This indicates that dissociation could mediate the relationship of childhood sexual abuse to high school performance.

\section{Limitations of the study}

There are several limitations to the study. Both samples were from a college population; therefore, the results can not necessarily be generalized to the general population. In addition, there could be a serious bias from college samples, since they exclude many people who may be troubled, disorganized, or of below average intelligence. However, as students confront the developmental challenges of their college years, a history of sexual abuse can be detrimental (Witchel, 1991). Furthermore, the meaning of high school GPA varied from one school to another. Another concern was the use of retrospective data gathered regarding the women's high school GPA, which depended on them remembering back to their first year in high school. However, in 
general, it is beneficial to study college students, because they are still fairly close in time to their childhood experiences and would suffer from less memory distortion than would older people questioned about a comparable event. Furthermore, now that time has passed they may have been more willing to discuss what occurred in their childhood. Schiller (1988) found that fifty-two percent of respondents reported that they never told anyone about their incest until reaching adulthood.

In addition, these are self-reported measures. Therefore a "halo effect" could have occurred, where the women would tend to answer in a socially positive way. This could also cause women to under-report childhood sexual abuse. To counter this effect the subjects were told that their answers would be confidential and that responding honestly was important to the study.

Furthermore, the small samples limit the number of variables that could be measured. Larger samples could enable the investigation of the relationship between sexual abuse and other measures like body image, victimization, and coping. In the future, with increased respondents a study could also examine more school measures like attitudes about women's past and current school experiences.

\section{: Future research ideas}

Various directions for future research and intervention are suggested by this study. This same study could be implemented during students' freshman year in high school and continued until their senior year in college. This would eliminate the problems with gathering retrospective and self-report data regarding their school functioning. In addition, the significant trends found in this study regarding academic ability could be further investigated. 
In terms of other research, another aspect to investigate would be gender differences by expanding the scope and including men in a study. Males abused as children are usually abused by people outside the family. In addition, they have the added pressure of the abuse having homosexual overtones, since they are typically abused by males. Moreover, males tend to sustain more frequent and serious injuries regarding physical and sexual abuse (Rosenthal, 1988; Hunter, 1990)

In addition, questioning the participants overall childhood abuse history including physical abuse and neglect, not just sexual abuse, would give a clearer picture of the respondents. A distinct picture could emerge by comparing and contrasting the different abusive histories in relation to different school measures and symptomatology variables. Some researchers have shown relationships between other types of abuse and adult functioning (e.g., Briere, 1992; Betz, Petretic-Jackson, Katsikas, Ames, Pitman, \& Lawless, 1993; Petretic-Jackson, Pitman, Betz, Katsikas, Ames, \& Lawless 1993).

Briere and Runtz (1988) investigated the multivariate correlates of childhood psychological and physical maltreatment among 251 college women. They found that maternal and paternal physical and psychological abuse was typically rated as present in the same families. In addition, they discovered that general parental abusiveness was associated with symptomatology measured by the Hopkins symptom checklist, as well as dissociation and suicidal ideation. These findings further suggest that it may be inappropriate to only focus on one form of abuse, since other types of abuse may be present as well.

Furthermore, having participants indicate whether they have a history of school problems or learning disabilities would enable the researcher to take into account these 
confounding variables. Adult victimization should also be included to determine whether this influences people's current school perceptions. A comparison of a college sample with a clinical or community sample could be done, since it has been said non-college samples would be more likely to exhibit problems with school and overall functioning.

Another area that should be explored is using different types of statistics like structural equation modeling. In the current study, dissociation was significantly correlated to high school grade point average (GPA), whereas social support was significantly correlated to Scholastic Achievement Test (SAT), which could indicate the need for mediating variables. This could mean that dissociation mediates the relationship between GPA and childhood sexual abuse, whereas social support mediates the relationship between sexual abuse and SAT scores. A structural equation model would allow the study of theses various relationships in a more detailed and meaningful way.

Intervention implications of this study indicate that whereas the relationship between childhood sexual abuse and some school performance measures do not hold up over time, interpersonal relationships may lower school functioning during the 11th grade. This indicates that whereas the effects of sexual abuse may appear to have dissipated there are still issues that may need to be dealt with. This study demonstrates that this may be the time to intervene with women, before they become involved in self-destructive relationship patterns that lead to re-victimization.

In summary, the data gathered for this study supported the stated hypotheses that whereas overall, women who were sexually abused in childhood may function well in certain areas, they also indicate poorer functioning in a variety of important areas. The findings of this study, given the limitations and the need for replication, clearly deserve 
serious attention and have implication for intervention. 
Table 1: Descriptive Data from Abused and Non-abused Participants

Age:

Abused $\quad$ Non-abused $\quad \underline{F}$

Year in School:

Mean $=20 \quad$ Mean $=19$

Freshman

$36(72.0)$

-ns-

Sophomore

$11(22.0)$

Junior

2(4.0)

$10(20.0)$

Senior

$1(2.0)$

2(4.0)

2(4.0)

Ethnicity:

White

African-American

$38(76.0)$

$4(8.0)$

Asian

2(4.0)

$3(6.0)$

Latino

$3(6.0)$

Gross Family Income Past year:

over 5,000

$1(2.0)$

5-14,999

$6(12.2)$

15-24,999

13(26.5)

25-34,999

$5(10.2)$

35 \& over

24(49.0)

$5.39 *$

$4(8.2)$

$4(8.2)$

$18(16.3)$

33(67.3)

Current living Arrangement:

Single

Married

24(48.0)

2(4.0)

Committed/Monogamous

$18(36.0)$

44(88.0)

2(4.0)

$1(2.0)$

3(6.0)

Living with Lover

6(12.0)

Counseling

Yes

No

$6(12.0)$

44(88.0)

-ns-

$50(100.0)$

Parental Status

Married

Separated

33(70.2)

$1(2.1)$

12(25.5)

Never Married

$1(2.0)$

31(62.0)

19(38.0)

-ns-

ns - non-significant; * .05 
Table 1 continued

Descriptive Data from Abused and Non-abused Participants.

Status of Maternal Grandmother

$\begin{array}{ll}\text { Abused } & \text { Non-abused } \\ 38(76.0) & 35(70.0) \\ 12(24.0) & 15(30.0) \\ \text { Mean }=8 & \text { Mean }=8\end{array}$

Status of Maternal Grandfather

Living -Yes

20(41.7)

-ns-

Living -No

How old when died

28(58.3)

22(41.7)

Mean $=10$

28(58.3)

Mean $=10$

Status of Paternal Grandmother

Living -Yes

$31(64.6)$

-ns-

Living -No

17(35.4)

$34(68.0)$

How old when died

Mean $=12$

16(32.0)

Mean $=10$

Status of Paternal Grandfather

Living -Yes

23(46.9)

$17(34.0)$

Living -No

26(53.1)

33(66.0)

How old when died

Mean $=8$

Mean $=6$

Status of Mother

$47(94.0)$

Living -Yes

Living -No

3(6.0)

$47(94.0)$

How old when died

Mean $=21$

3(6.0)

Mean $=10$

Status of Father

47(94.0)

Living -Yes

Living -No

How old when died

3(6.0).

47(94.0)

Mean $=20(2 \& 37)$

Mean $=5$

Status of Sister

Living - Yes

Living -No

How old when died

39(95.1)

2(4.9)

$33(97.1)$

Mean $=4$

1(2.9)

-nS-

-ns-

Status of Brother

Living - Yes

Living -No

36(97.3)

1(2.7)

$29(90.6)$

How old when died

Mean $=2$

Mean $=20$

ns - non-significant 
Table 2: Sexual Abuse Data for Abused Participants

Victim's Age

Abuser's Age

Sex of Abuser

Male

Female

Relationship of abuser to victim

Father

Stepfather

Brother

Uncle/Aunt

Cousin

Friend

Stranger

Grandparent

Mother's boyfriend

Characteristics of Abuse

Invitation to do something sexual

Kissing/hugging sexual way

Person showing sex organs

You showing sex organs

Person fondling you

You fondling person

Person touch your sex organs

You touch person's sex organs

Intercourse $\mathrm{W} / \mathrm{O}$ penetration

Intercourse

Other
Under 12 years $12 \&$ Over

Mean $=44(7.59) \quad$ Mean $=16(14.44)$

Mean $=44(19.24) \quad$ Mean $=16(35.56)$

39(90.7)

$4(9.3)$

$16(100.0)$

$1(2.4)$

$1(2.4)$

$6(14.6)$

$6(14.6)$

$8(19.5)$

12(29.3)

$7(17.1)$

1(6.3)

1(6.3)

3(18.8)

6(37.5)

$3(18.8)$

1(6.3)

1(6.3)

29(82.9)

$8(50.0)$

15(41.7)

25(73.5)

$8(50.0)$

$4(25.0)$

12(35.3)

30(78.9)

$4(25.0)$

$8(50.0)$

$8(23.5)$

$3(18.8)$

$4(25.0)$

4(25.0)

2(12.5)

$3(18.8)$

2(6.9)

8(50.0)

27(77.1)

13(39.4)

4(13.3)

----

9(56.3)

$5(31.3)$

2(12.5)

17(43.6)

14(35.9)

8(20.5)

Abuser drinking

Yes

No

4(10.0)

7(46.7)

35(87.5)

7(46.7)

Both

1(6.7) 
Table 2 continued

Sexual Abuse Data for Abused Participants.

Frequency of abuse

Once

Seldom

Few Times

Often

Duration of Abuse

Reaction at time of abuse

Fear

Shock

Surprise

Interest

Pleasure

Disclosure of Abuse

No one

Mother

Brother/sister

Friend

Other

Everybody

Parents

No one

One person

Two people

Three or more people

Age when Disclosed

Feelings about abuse

Mostly Positive

Neutral

Mostly Negative

Negative
22(52.4)

16(14.3)

$10(23.8)$

$4(9.5)$

Mean $=9.2(371$ times $)$

28(70.0)

$3(7.5)$

$5(12.5)$

3(7.5)

1(2.5)

13(29.5)

11(25.0)

2(4.2)

$8(18.2)$

2(4.5)

3(6.8)

$5(11.4)$

13(29.5)

16(36.4)

7(15.9)

8(18.2)

Mean $=13.4$

1(2.3)

12(27.9)

2(4.7)

28(65.1)
$8(50.0)$

2(12.5)

$4(25.0)$

2(12.5)

Mean $=16.3(31$ times $)$

9(56.3)

$5(31.3)$

$1(6.3)$

$1(6.3)$

2(12.5)

$4(25.0)$

1(6.3)

4(25.0)

$1(10.5)$

$4(25.0)$

2(12.5)

7(43.8)

$3(18.8)$

4(25.1)

Mean $=16.9$

$5(31.3)$

$5(31.3)$

$6(37.5)$ 


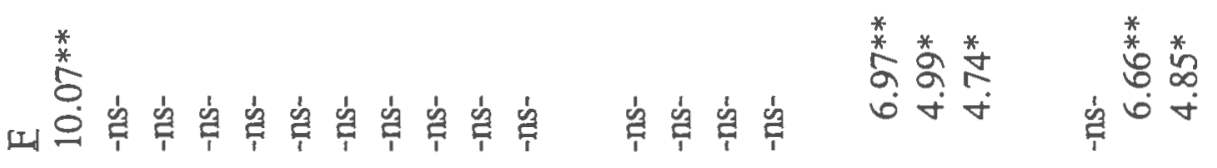

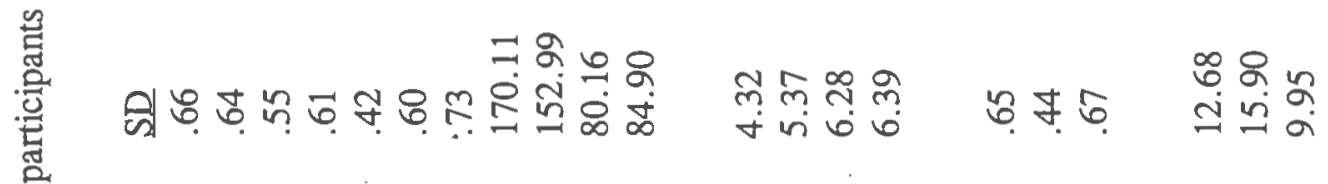

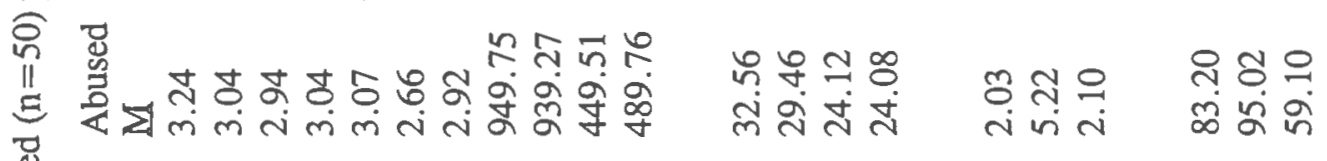

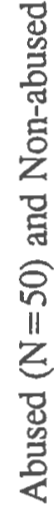

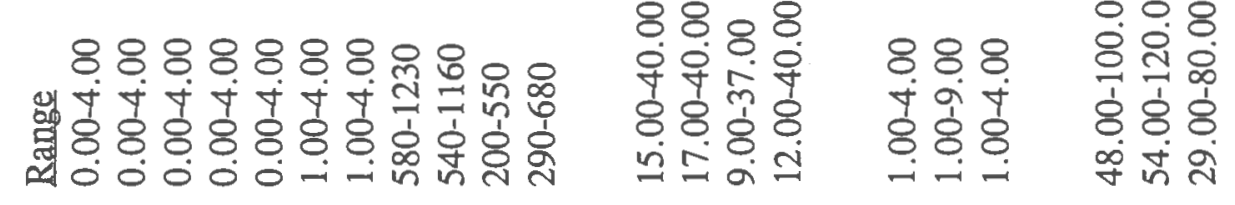

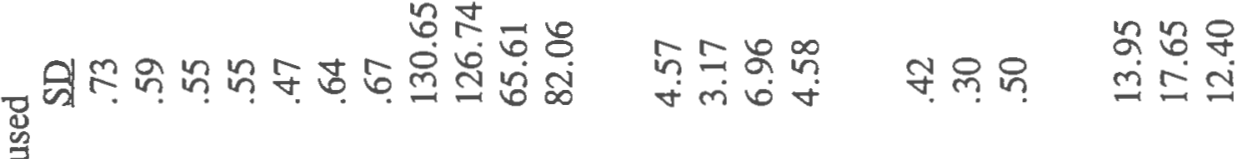

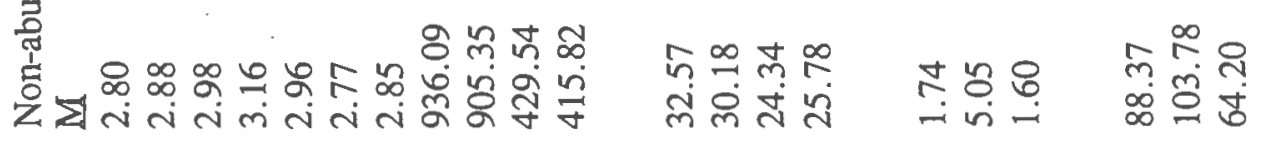
पे
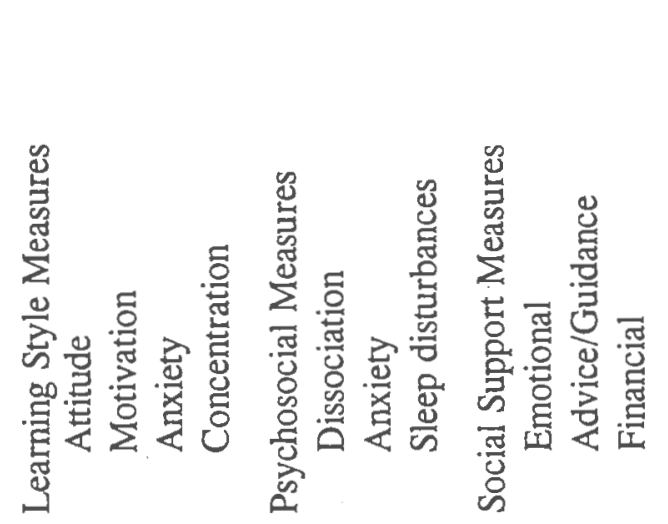
Table 4: Summary of study predictions and outcomes

Prediction

Negative Feeling Variables:

Outcome

1. For women who report abuse there will be a positive relationship between duration and negative feelings regarding the abuse.

2. For women who report abuse there will be a positive

No Relationship relationship between force and negative feelings regarding the abuse.

3. For women who report abuse there will be a positive No Relationship relationship between disclosure and negative feelings regarding the abuse.

School Variables:

4. Abused women will report less belief in their scholastic ability, as measured by the Self-Perception Profile, than the nonabused women.

5. Abused women will report less belief in their intellectual ability, as measured by the Self-Perception Profile, than the nonabused women.

6. Abused women will report poorer academic

No Difference performance, as measured by the SAT score, than the nonabused women.

7. Abused women will report poorer academic performance, as measured by the GPA score, than the nonabused women.

No Difference

No Difference

Groups Differ in unexpected direction

Learning Styles Variables:

8. Abused women will report poorer attitude, as measured

No Difference by the LASSIE, than the nonabused women.

9. Abused women will report poorer motivation, as

No Difference measured by the LASSIE, than the nonabused women.

10. Abused women will report greater learning anxiety, as

No Difference measured by the LASSIE, than the nonabused women.

11. Abused women will report poorer concentration, as

No Difference measured by the LASSIE, than the nonabused women.

Psychosocial Variables:

12. Abused women will report greater pathological symptoms, as measured by the TSC- 33 , than the nonabused women.

Groups Differ

in expected

direction 
Table 4 continued

Summary of study predictions and outcomes

13. Abused women will report greater dissociation, as measured by the TSC-33, than the nonabused women.

14. Abused women will report greater anxiety, as measured by the TSC-33, than the nonabused women.

15. Abused women will report greater sleep disturbance, as measured by the TSC-33, than the nonabused women.

Social Support Variable:

16. Abused Women will report poorer emotional social No Difference support, as measured by the SS-B than the nonabused women.

17. Abused Women will report poorer financial social support, as measured by the SS-B than the nonabused women.

18. Abused Women will report poorer advice/guidance social support, as measured by the SS-B than the nonabused women.

Groups Differ in expected direction

Groups Differ in expected direction

Groups Differ in expected direction Groups Differ in expected direction

Groups Differ in expected direction 


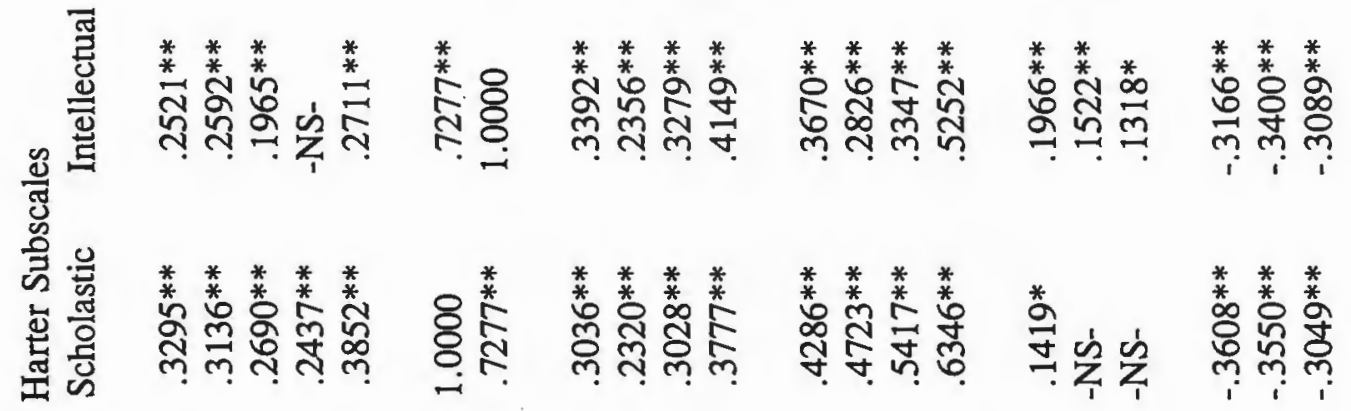

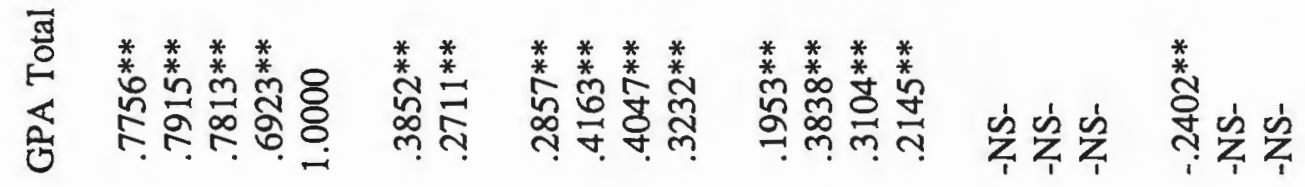

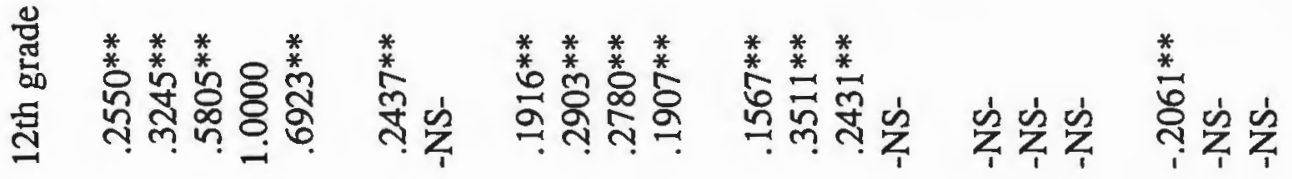

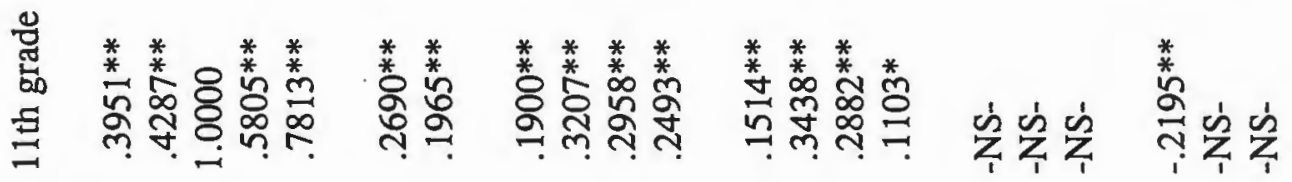

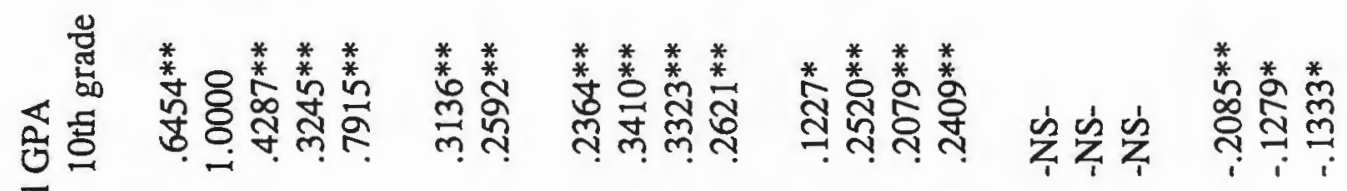

용

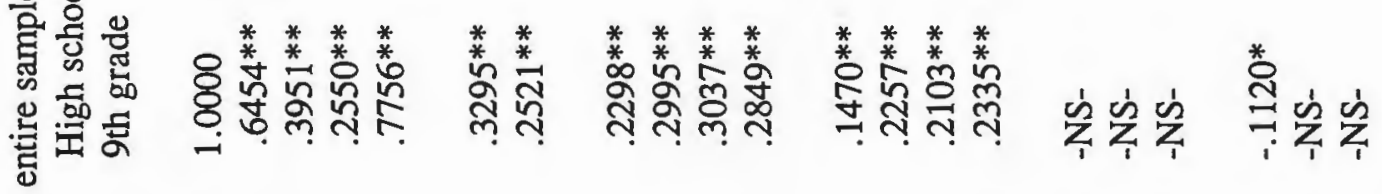

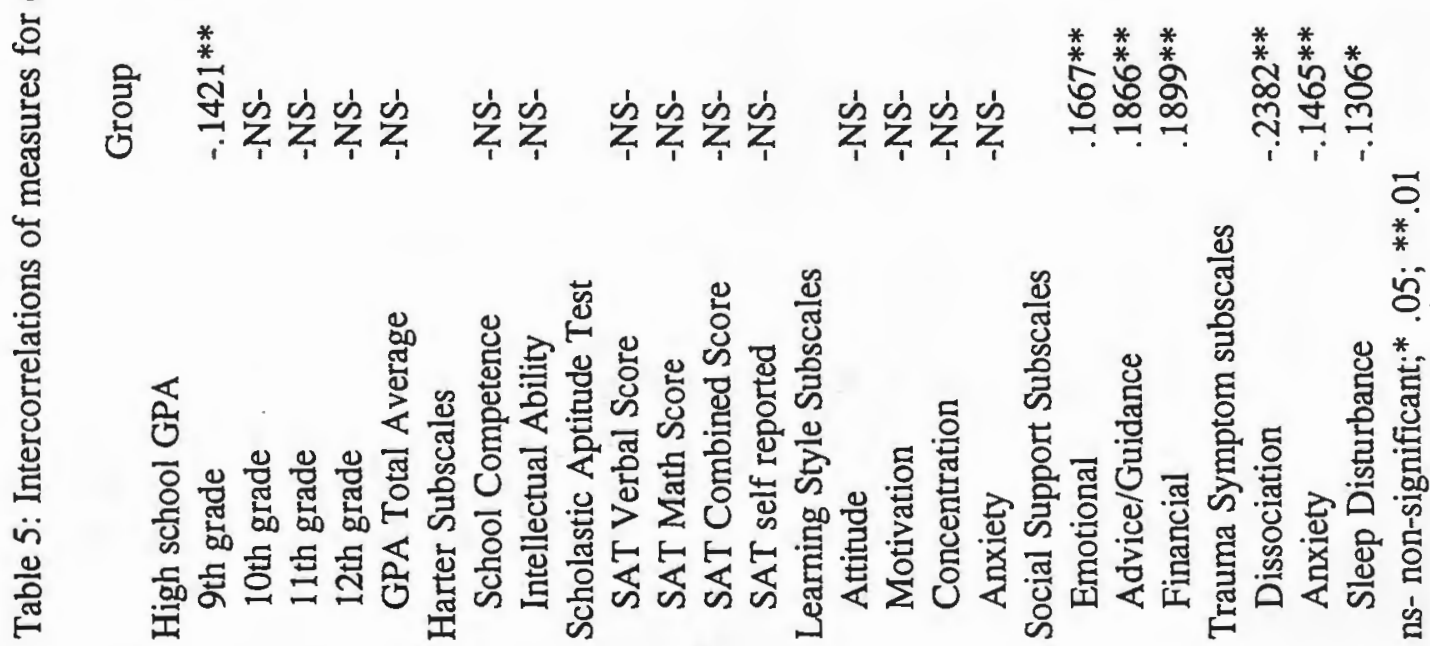




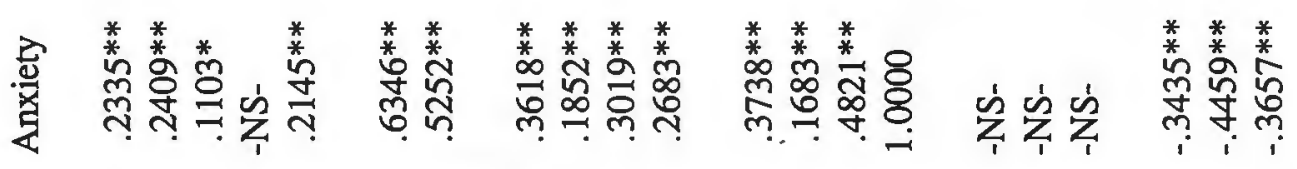

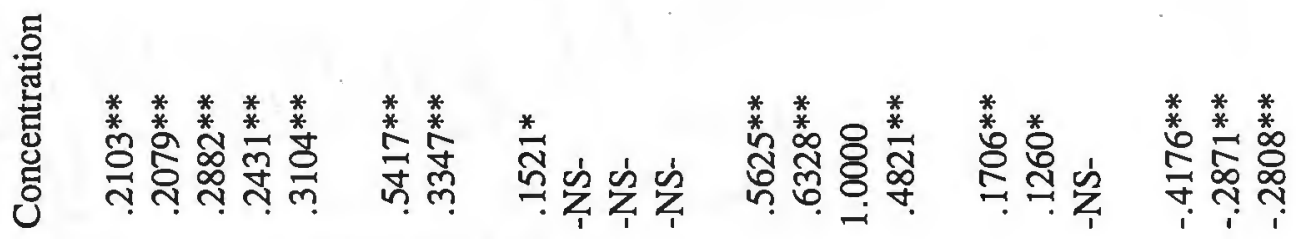

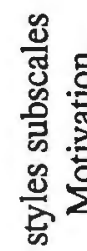

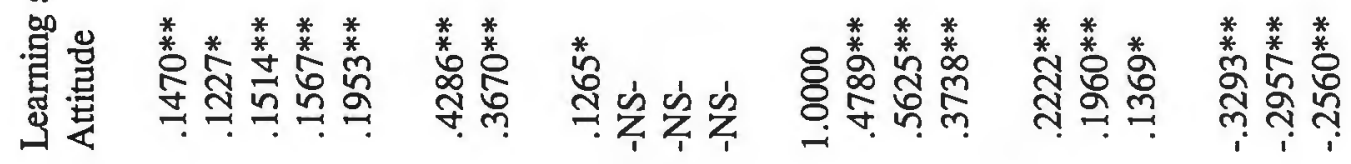

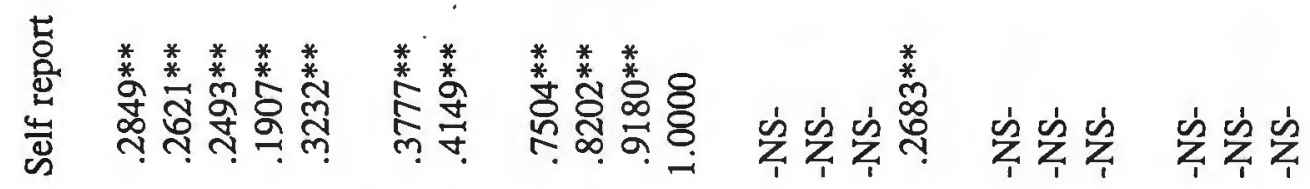

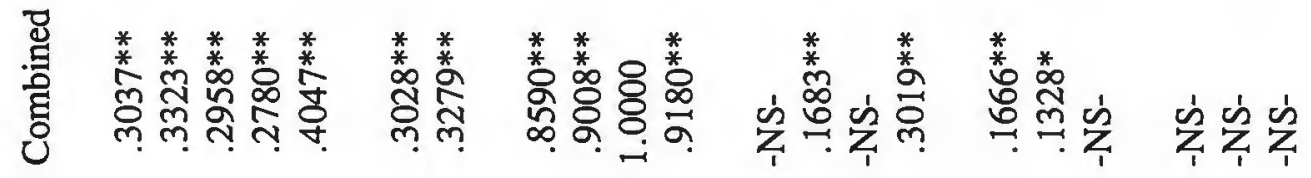

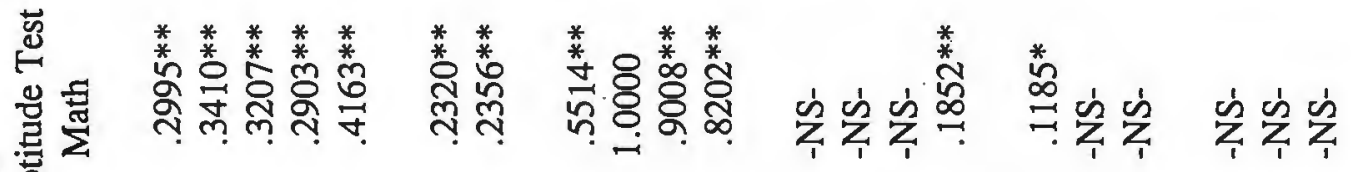

高完

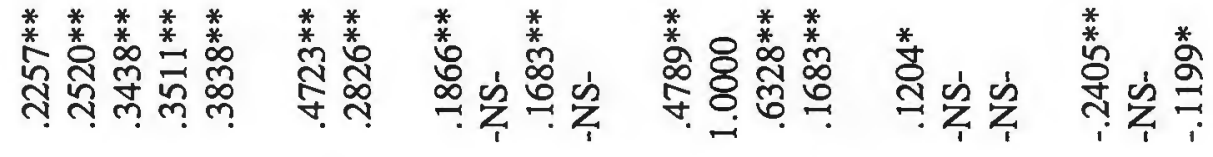

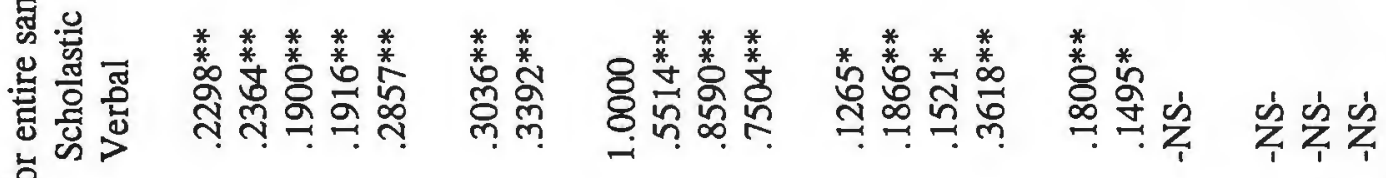

s

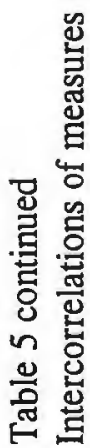

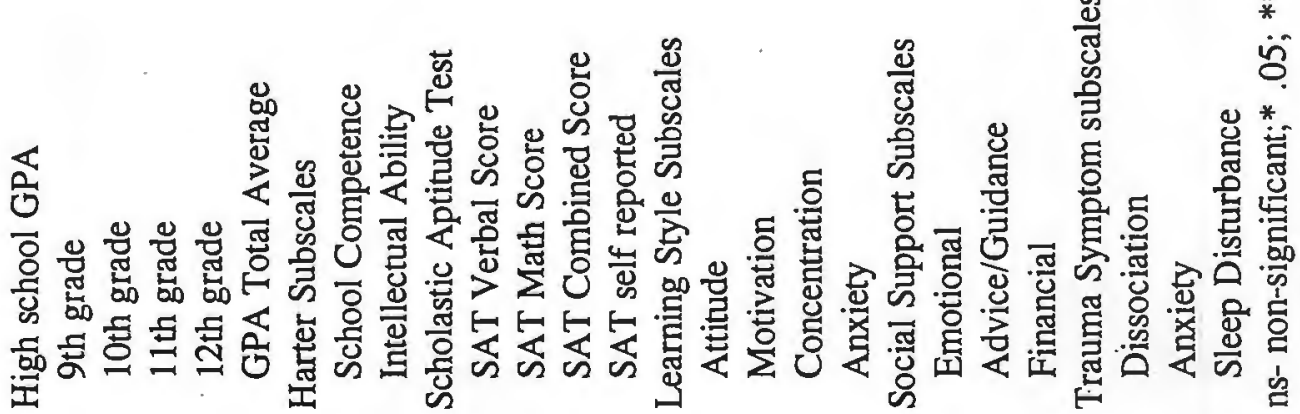




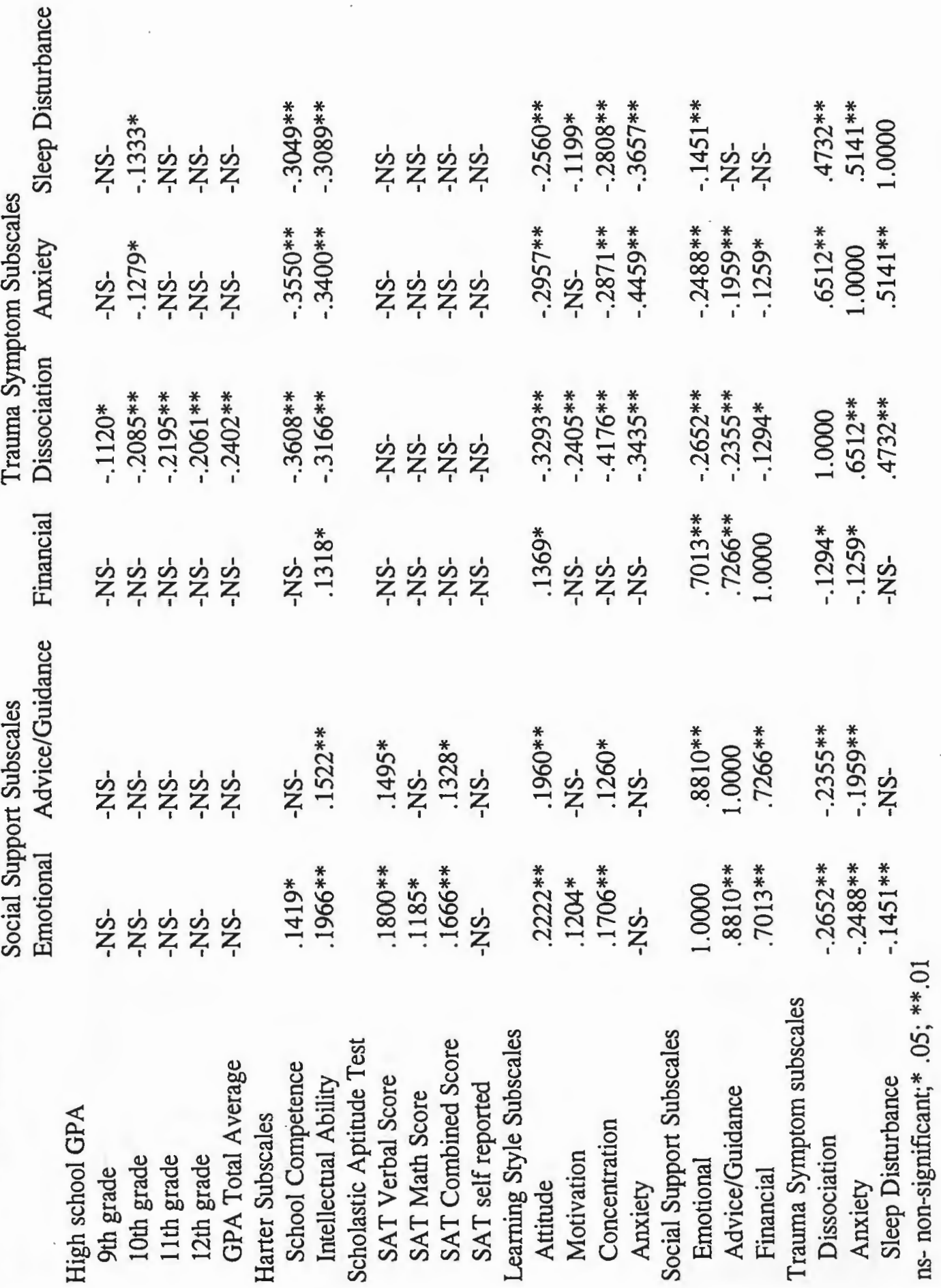




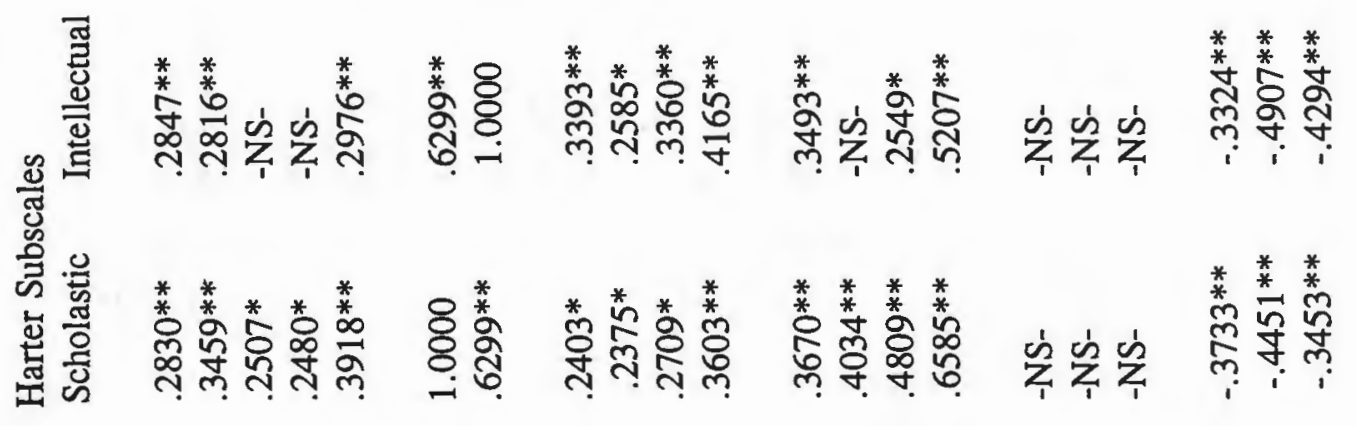

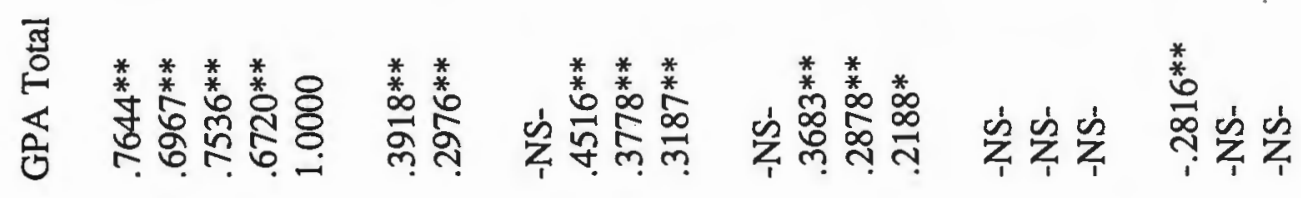

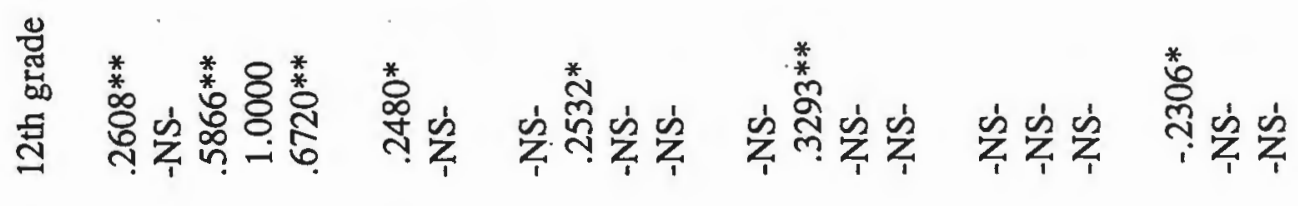

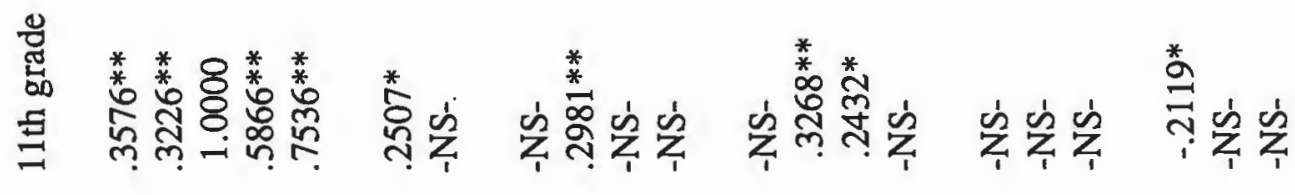

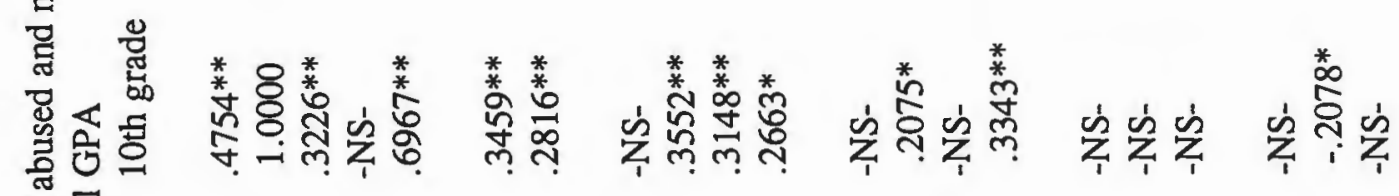

范

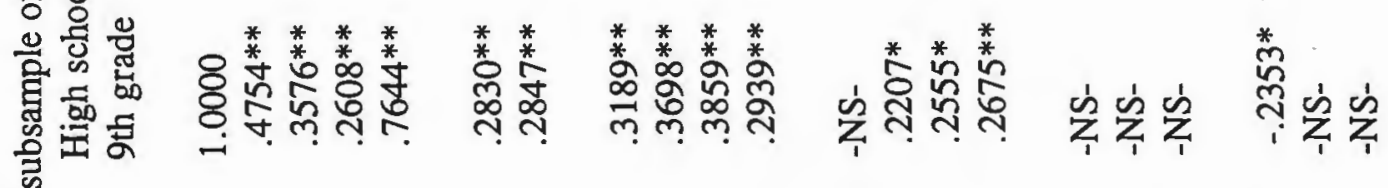

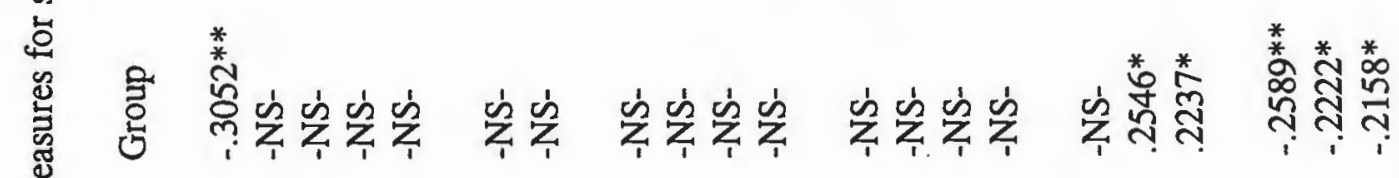

点

曾

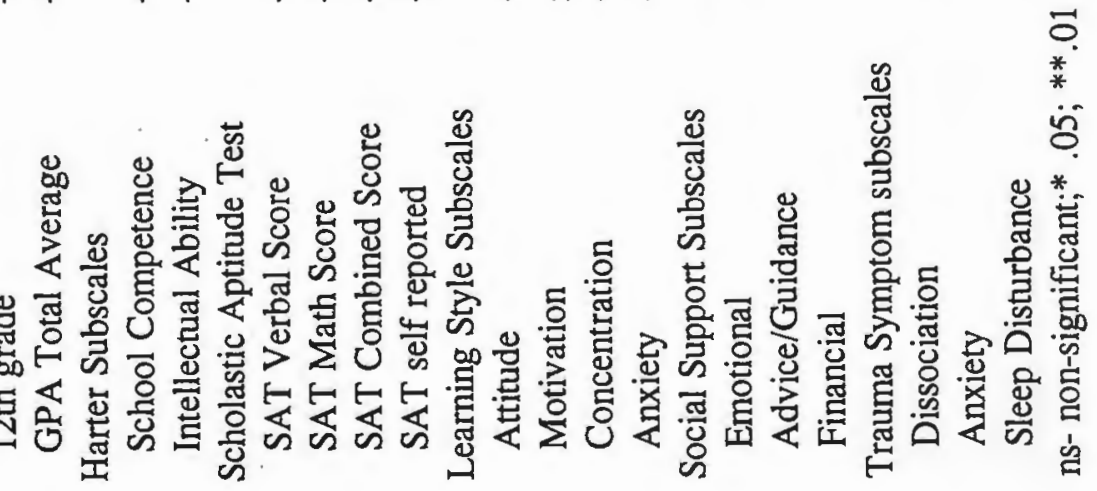




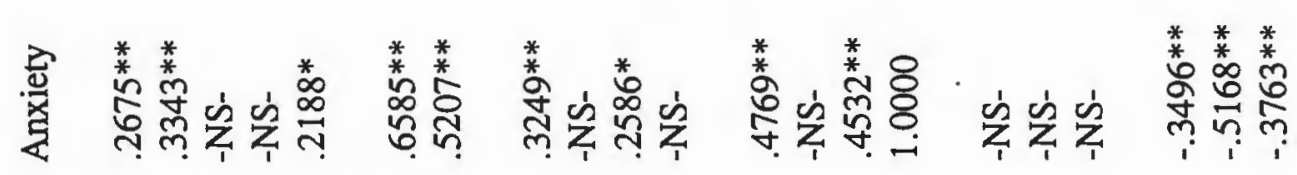

总

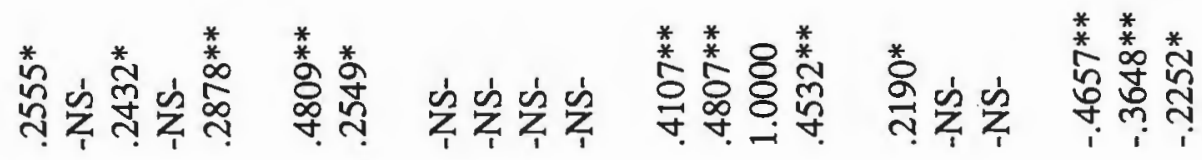

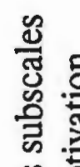

造

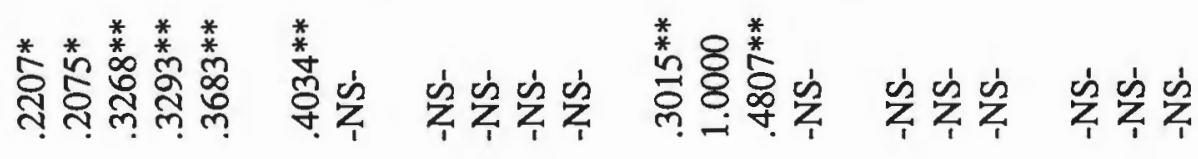

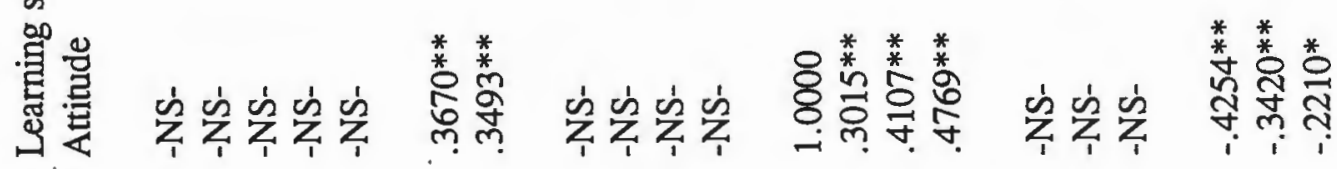

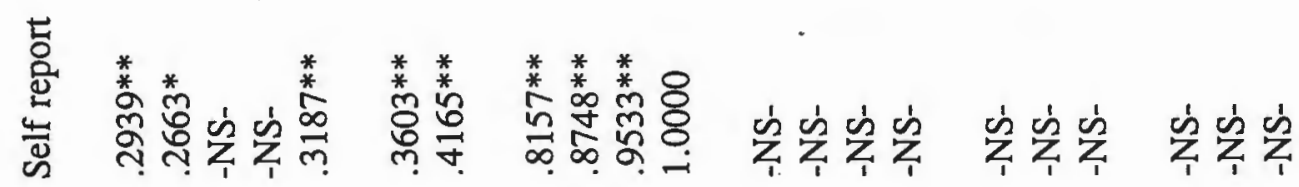

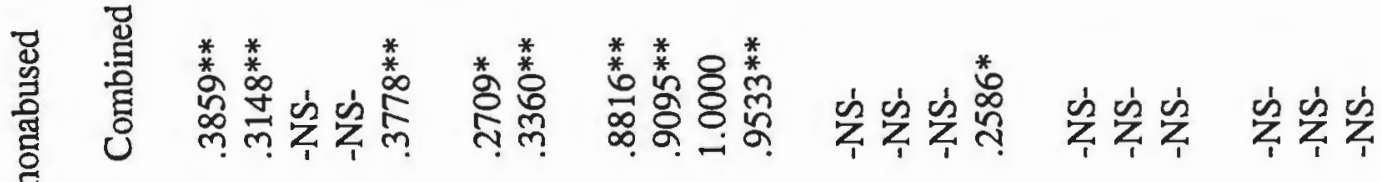

을

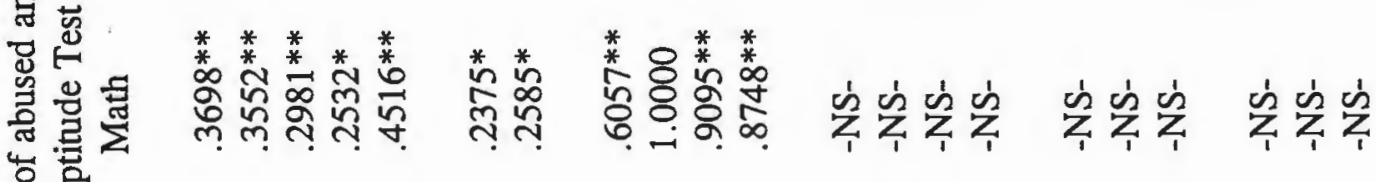

它

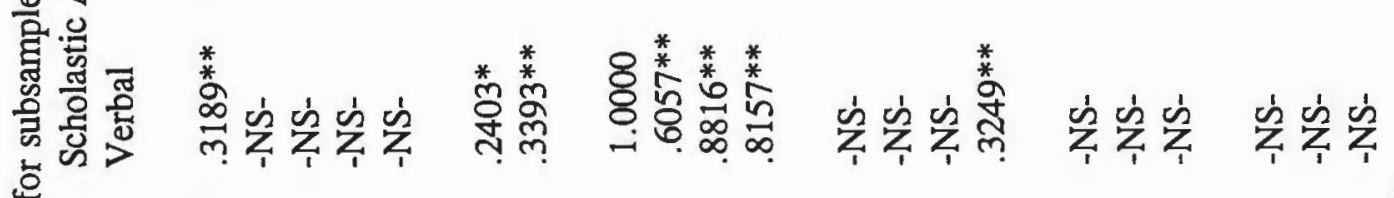

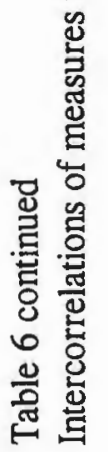

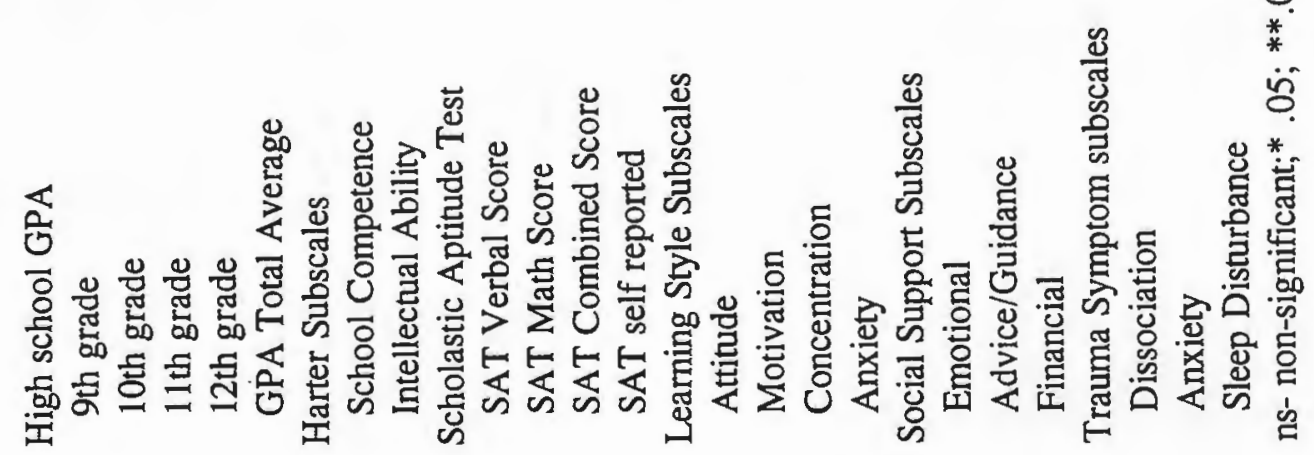




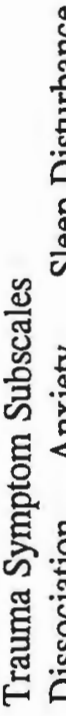

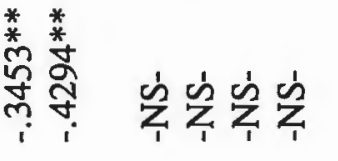

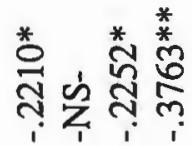

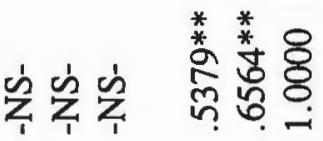
$\frac{\mathscr{O}}{\mathcal{J}}$

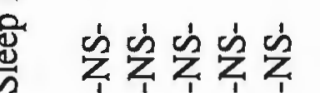

$\stackrel{*}{*}$

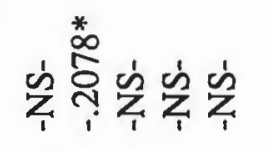

势 守

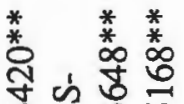

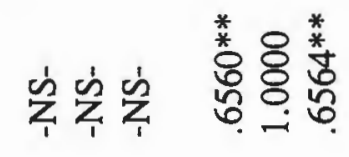

氶

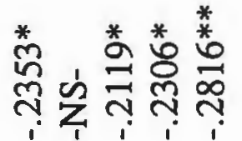

$\stackrel{*}{\stackrel{*}{*}} \stackrel{*}{*} \underset{m}{*}$

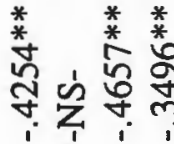

苍苜官

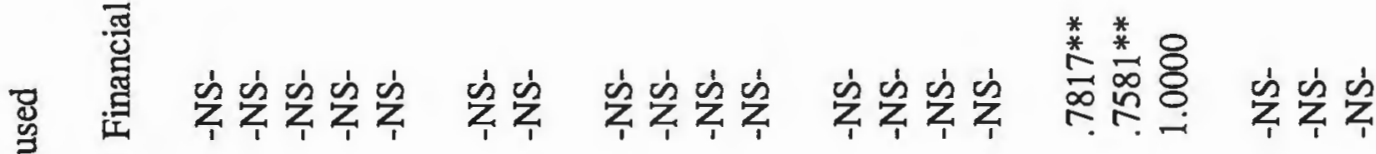

Z

递

马ु

色产送

它

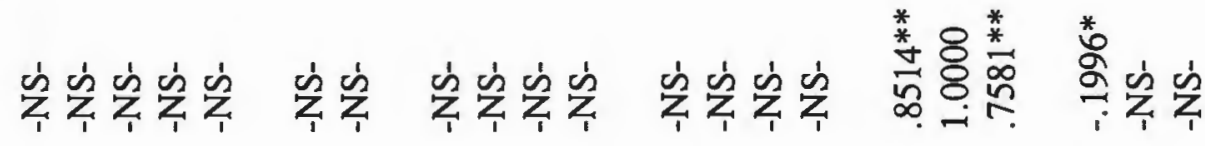

$\stackrel{0}{\circ}$

쟁 ธ

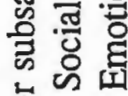

速

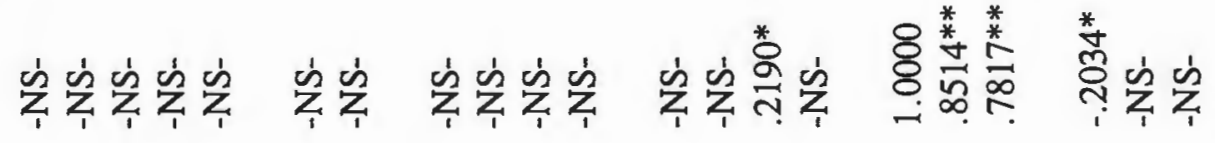

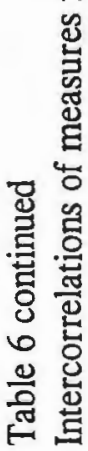

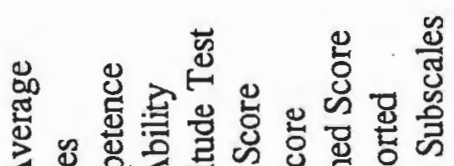

范

o

,

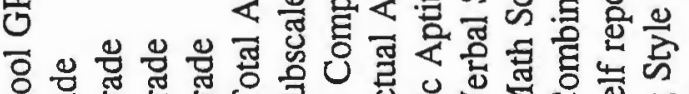

త్త్ర

जิ

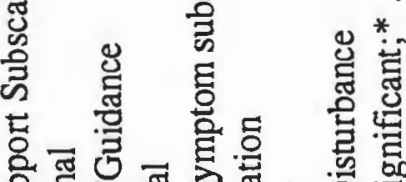

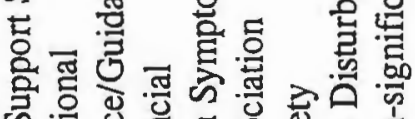

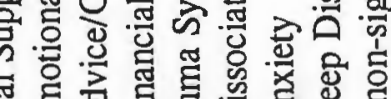

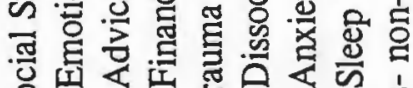
员证 
Figure 1: Means of school measures for abused and nonabused participants 

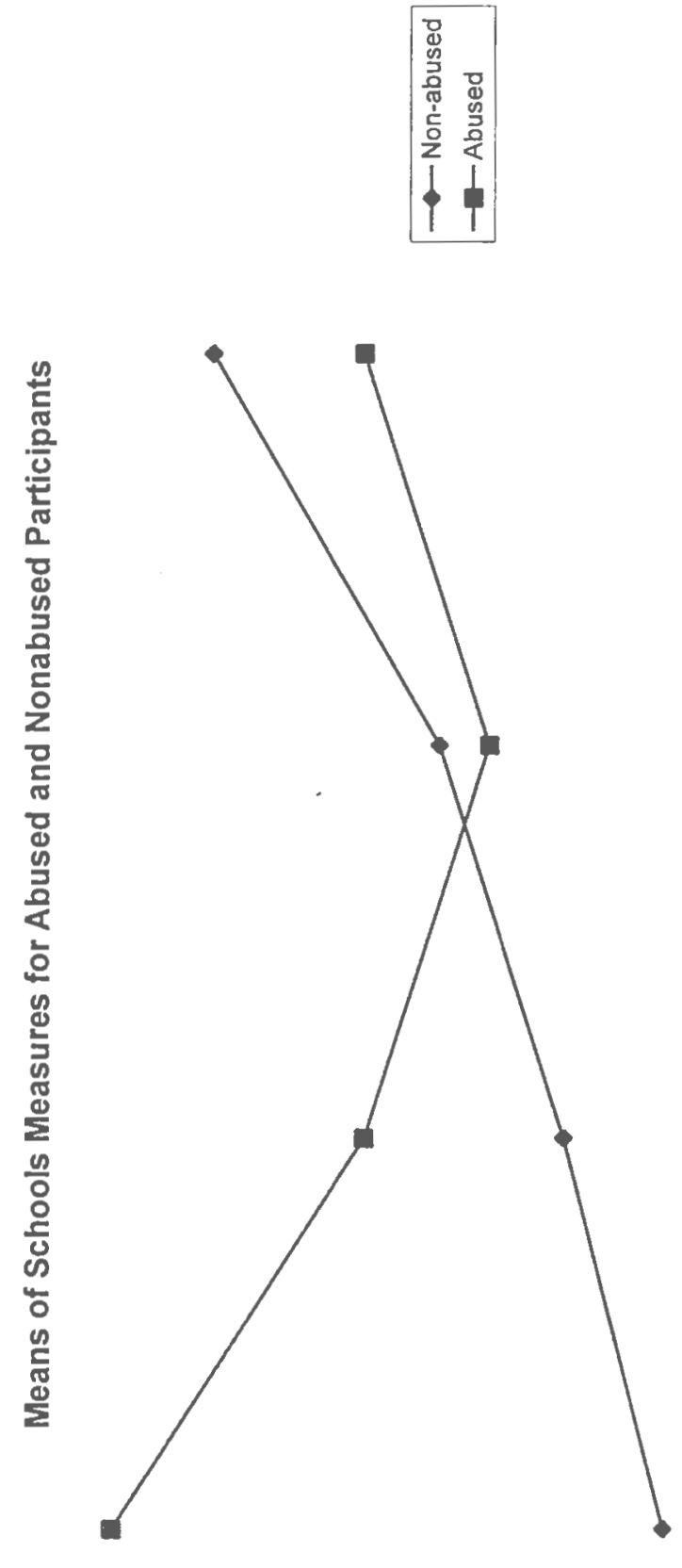

T芒

5
5
0
0

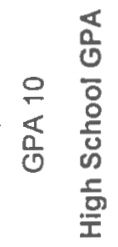

0
0
0
0 
Figure 2: Means of school measures for abused ( $7 \&$ under ; 8 \& over) and nonabused participants 


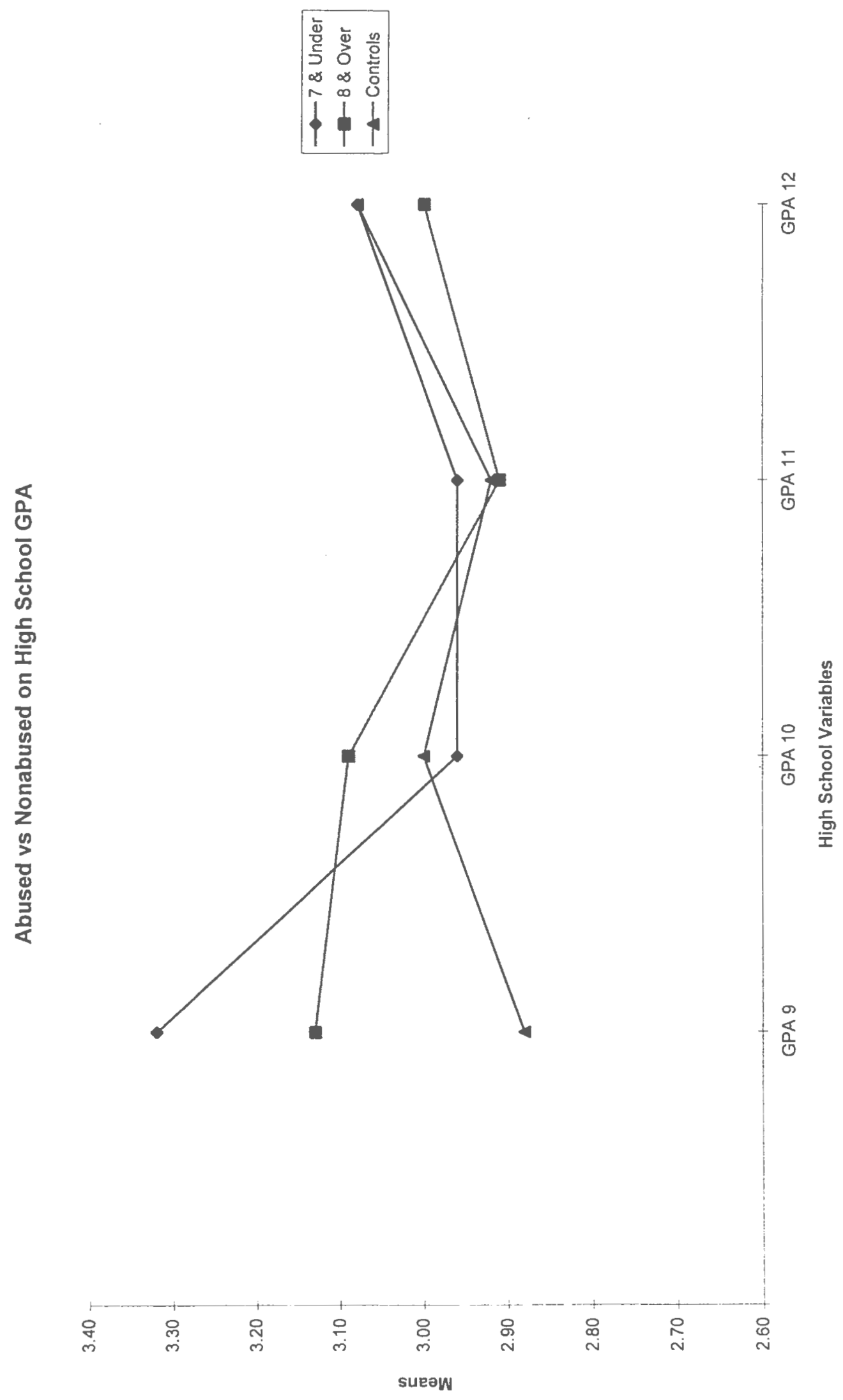

65 


\section{Appendix A}


Protocol 1: Consent form

\author{
The University of Rhode Island \\ Department of Psychology \\ Kingston, RI 02881
}

Childhood Experiences, Adult Functioning, and Sexuality

\title{
CONSENT FORM FOR RESEARCH
}

This study is a research project, conducted as part of my thesis in clinical psychology, University of Rhode Island. The purpose of this study is to examine the relationship between childhood sexual experiences and women's current life experiences.

\section{MUST BE 18 OR OLDER TO PARTICIPATE IN THIS STUDY.}

My participation in this research project requires that I meet with an examiner once, and complete a questionnaire. This questionnaire will take approximately one hour to fill out. If I decide to participate, I will be asked to provide consent to obtain my SAT score from University College. Now I will be asked to fill out a questionnaire, which includes questions about childhood sexual experiences, school, feelings, and attitudes.

If the study causes me any injury, I should write or call the office of the Vice Provost for Research, 70 Lower College Road, University of Rhode Island, Kingston, Rhode Island, telephone: (401) 792-2635.

Although there will be no direct benefit to me for taking part in this study beyond meeting a requirement for class, the researcher may examine the relationship between childhood sexual experiences and women's current life experiences.

My part in the study will be confidential. I will be assigned a participant identification number which will be used to code my questionnaire. The principal investigator will retain a list equating my name and my ID number which will be kept in a locked file cabinet separate from my questionnaire. After obtaining my SAT score, she will use this list to transfer my SAT score to a sheet coded with my ID number, and will destroy information linking my name to my SAT score.

The decision whether or not to take part in this study is up to me. I do not have to participate. If I decide to take part in the study, I may quit at any time. Whatever I decide will in no way effect my status as a student. If I wish to quit I simply inform Patricia Lee at 792-5560 of my decision.

If I are not satisfied with the way this study is performed, I may address my complaints with Patricia Lee at 792-5560, anonymously, if I choose. In addition, I may contact the office of the Vice Provost for Research, 70 Lower College Road, University of Rhode Island, Kingston, Rhode Island, telephone: (401) 792-2635.

I have read the Consent form. My questions have been answered. My signature on this form means that I understand the information and I agree to participate in this study.

Signature of Participant

Typed/printed Name
Signature of Researcher

Typed/printed Name

Date

$\overline{\text { Date }}$ 
Protocol 2: Consent form for SAT

\section{REQUEST FOR CONFIDENTIAL INFORMATION}

Subject name: Date of Birth:

I, hereby authorize:

\section{Patricia Lee \\ University of Rhode Island \\ CPRC \\ Flagg Road \\ Kingston, Rhode Island 02881}

to request from: University College

University of Rhode Island

Kingston, RI 02881

The following information from my records (please be specific):

My SAT score and high school GPA from my admission records.

This information is needed for the purpose of:

To examine the relationship between childhood sexual experiences and women's adult functioning.

Specification of the date, event or condition upon which this consent expires:

I will be assigned a participant identification number which will be used to code my questionnaire. The principal investigator will retain a list equating my name and my ID number which will be kept in a locked file cabinet separate from my questionnaire. After obtaining my SAT score and GPA, she will use this list to transfer my SAT score and GPA to a sheet coded with my ID number, and will destroy information linking my name to my SAT score and GPA.

Date Signed

Subject's Signature 


\section{Protocol 3: General Instructions}

An area of concern in our society is the relationship of childhood sexual experiences to women's current life experiences. As part of a thesis, we hope to expand our understanding of this particular and important area of human development. This questionnaire contains items regarding personal experiences and attitudes about school and sexual behavior.

Please note: You responses to this questionnaire will be held in strict confidence. In addition, to preserve your right to privacy,

\section{DO NOT PUT YOUR NAME OR IDENTIFICATION ANYWHERE ON THIS QUESTIONNAIRE.}

\section{YOU MUST BE 18 OR OLDER TO FLL OUT THIS QUESTIONNAIRE.}

It is not necessary to know who you are; only your experiences and attitudes are important for the purpose of this research. It is hoped that, by your cooperation and assistance of others like you, we, as a society, may gain a better understanding about this important area of human society and development. Completing this questionnaire is voluntary.

This survey contains items which make reference to human sexual behavior and childhood sexual abuse. If you do not desire to be exposed to such statements or remarks, please do not go any further. In this case, return the questionnaire to the investigator.

If you decide to participate in this survey, please answer all questions honestly and to the best of your ability. It is important that we have truthful information.

Remember: All information is kept in strict confidence.

\section{DO NOT PUT YOUR NAME OR IDENTIFICATION ANYWHERE ON THIS QUESTIONNAIRE OR ON THE RESPONSE SHEET.}

Thank you for agreeing to participate in this research.

Completing the whole questionnaire should take around one hour.

\section{PLEASE MARK YOUR RESPONSES FOR THE QUESTIONS THAT HAVE SCALES AT THE TOP ON THE COMPUTER RESPONSE SHEETS AS INSTRUCTED IN THE QUESTIONNAIRE.}

If you have any questions about the survey or about how or where to mark your responses, please contact the experimenter.

If these questions are upsetting and you want to talk, please use the phone numbers below. Counseling Center (URI) (410) $792-2288$ Women's Resource Center (401) $782-3990$ Sojourner House (401) $431-1871$ or (401) $658-4334$ in Northern RI

You may tear this page off to keep and then begin the survey. Again, please answer all questions as honestly and as accurately as possible. 
Appendix B 


\section{Thesis Measures}

Measure 1: Background information

1. Please fill in your age

2. Year in College:
a. Freshman
c. Junior
b. Sophomore
d. Senior

3. Race or cultural group:
a. White
c. Afro-American
b. Asian
d. Latino
e. Other

4. Income: In the past year, what was your family's(parents) gross income?
a. less than $\$ 5,000$
c. $\$ 15,000$ to 24,999
b. $\$ 5,000-14,999$ d. $\$ 25,000$ to $\$ 34,999$
e. $\$ 35,000 \&$ above

5. What is your current relationship status?:
a. single, uncommitted
c. In committed, monogamous relationship
b. married
d. Living with lover

Measure 2: Therapy questions

1. Are you currently receiving counseling or professional help from a counselor or therapist for a problem?
a. Yes
b. No

2. If in counseling how long have you been receiving counseling?
a. Never
c. 6 months to a 1 year
b. Less then 6 months
d. More than a year

3. If in counseling how often did you attend counseling?
a. Once a week
c. Once a month
b. Twice a week
d. Twice a month
e. Less than once a month 
Measure 3: Family status

1. Are your parents:
a. Married
c. Divorced
b. Separated
d. Never married

2. Please indicate whether your maternal grandmother is living and if not how old when she died.

a. Currently living

b. No longer living.

Please fill in the answer to the next question directly on the sheet How old were you when she died?

3. Please indicate whether your maternal grandfather is living and if not how old when he died.

a. Currently living

b. No longer living.

Please fill in the answer to the next question directly on the sheet How old were you when he died?

4. Please indicate whether your paternal grandmother is living and if not how old when she died.

a. Currently living

b. No longer living.

Please fill in the answer to the next question directly on the sheet How old were you when she died?

5. Please indicate whether your paternal grandfather is living and if not how old when he died.

a. Currently living

b. No longer living.

Please fill in the answer to the next question directly on the sheet How old were you when he died?

6. Please indicate whether your mother is living and if not how old when she died.

a. Currently living

b. No longer living.

Please fill in the answer to the next question directly on the sheet How old were you when she died?

7. Please indicate whether your father is living and if not how old when he died.

a. Currently living

b. No longer living.

Please fill in the answer to the next question directly on the sheet How old were you when he died? 
8. Please indicate whether all your sister(s) are living and if not how old when she died.

a. Currently living

b. No longer living.

Please fill in the answer to the next question directly on the sheet

How old were you when she died?

9. Please indicate whether all your brother(s) are living and if not how old when he died.

a. Currently living

b. No longer living.

Please fill in the answer to the next question directly on the sheet

How old were you when he died? 
Measure 4: Self-report of scholastic Aptitude Test (SAT)

1. My combined SAT SCORE was

Measure 5: Self-report of High School Grade Point Average (GPA)

1. What was your average grade (GPA) in 9th grade?
a. A
c. C
b. B
d. D

e. F

2. What was your average grade (GPA) in 10th grade?
a. A
c. C
b. B
d. D

e. F

3. What was your average grade (GPA) in 11th grade?
a. A
c. C
b. B
d. D

e. F

4. What was your average grade (GPA) in 12th grade?
a. A
c. C
b. B
d. D

e. F 
Measure 6: The Self-Perception Profile for College Students (Neemann, J., \& Harter, S.

First decide which one of the two parts of each statement best describes you; then go to that side of the statement and check whether that is just sort of true for you or really true for you. You will just check ONE of the four lines for each statement.

\begin{tabular}{|c|c|c|c|c|c|c|}
\hline $\begin{array}{l}\text { Really } \\
\text { True } \\
\text { for Me }\end{array}$ & $\begin{array}{l}\text { Sort of } \\
\text { True } \\
\text { for me }\end{array}$ & & & & $\begin{array}{l}\text { Sort of } \\
\text { true } \\
\text { for me }\end{array}$ & $\begin{array}{l}\text { Really } \\
\text { true } \\
\text { for me }\end{array}$ \\
\hline & & $\begin{array}{l}\text { 1. Some students feel } \\
\text { confident that they are } \\
\text { mastering their } \\
\text { coursework. (R) }\end{array}$ & But & $\begin{array}{l}\text { Other students do not } \\
\text { feel so confident. }\end{array}$ & & \\
\hline & & $\begin{array}{l}\text { 2. Some students do } \\
\text { very well at their } \\
\text { studies. (R) }\end{array}$ & But & $\begin{array}{l}\text { Other students don't do } \\
\text { very well at their } \\
\text { studies. }\end{array}$ & & \\
\hline & & $\begin{array}{l}\text { 3. Some students have } \\
\text { trouble figuring out } \\
\text { homework } \\
\text { assignments. }\end{array}$ & But & $\begin{array}{l}\text { Other students rarely } \\
\text { have trouble with their } \\
\text { homework } \\
\text { assignments. }\end{array}$ & & \\
\hline & & $\begin{array}{l}\text { 4. Some students } \\
\text { sometimes do not feel } \\
\text { intellectually competent } \\
\text { at their studies. }\end{array}$ & But & $\begin{array}{l}\text { Other students usually } \\
\text { do feel intellectually } \\
\text { competent at their } \\
\text { studies. }\end{array}$ & & \\
\hline & & $\begin{array}{l}\text { 5. Some students feel } \\
\text { like they are just as } \\
\text { smart or smarter than } \\
\text { other students. (R) }\end{array}$ & But & $\begin{array}{l}\text { Other students wonder } \\
\text { if they are as smart. }\end{array}$ & & \\
\hline & & $\begin{array}{l}\text { 6. Some students do } \\
\text { not feel they are very } \\
\text { mentally able. }\end{array}$ & But & $\begin{array}{l}\text { Other students feel that } \\
\text { they are very mentally } \\
\text { able. }\end{array}$ & & \\
\hline & & $\begin{array}{l}\text { 7. Some students feel } \\
\text { they are just as bright } \\
\text { or brighter than most } \\
\text { people. (R) }\end{array}$ & But & $\begin{array}{l}\text { Other students wonder } \\
\text { if they are as bright. }\end{array}$ & & \\
\hline & & $\begin{array}{l}\text { 8. Some students } \\
\text { question whether they } \\
\text { are very intelligent. }\end{array}$ & But & $\begin{array}{l}\text { Other students are very } \\
\text { happy being the way } \\
\text { they are. }\end{array}$ & & \\
\hline
\end{tabular}

Note: The final score for the two separate dependent measures is the mean of items $1,2,3,4$, for the SCHOLASTIC COMPETENCE composite; and items 5, 6, 7, 8, for the INTELLECTUAL ABILITY composite. The items with (R) following were reversed scored. Higher scores, therefore, indicate greater school perception range from 1 to 4 . 
All rights reserved. It is a violation of the law to copy any or all of this publication without written permission of the publisher. Do not reproduce this publication in any way using media including computer memory devices without written permission of the publisher.

Measure 7: The Learning and Study Strategies Inventory (LASSIE: Weinstein, Palmer, \&

Schulte, 1987)
Scale
A - Not at all typical of me
B - Not very typical of me
C - Somewhat typical of me
D - Fairly typical of me
E - Very much typical of me

1. I worry that I will flunk out of school. (R)

2. I don't care if I finish school as long as I find a husband/wife. (R)

3. I find that during lectures I think of other things and don't really listen to what is being said. (R)

4. I get discouraged because of low grades. (R)

5. I am up-to-date in my class assignments.

6. Problems outside of school- being in love, financial difficulties, conflict with parents, etc. cause me to neglect my school work. (R)

7. Even when studying materials are dull and uninteresting, I manage to keep working until I finish.

8. I feel confused and undecided as to what my educational goals should be. (R)

9. I come to class unprepared. (R)

10.I would rather not be in school. (R)

$11 . I$ am very tense when I study. (R)

12.I work hard to get a good grade, even when I don't like the course.

13.I often feel like I have little control over what happens to me in school. (R)

14. Even when I am well prepared for a test, I feel very anxious. (R)

15.I talk myself into believing some excuse for not doing a studying project. (R)

16. When I begin an examination, I feel pretty confident that I will do well.

17.I do not care about getting a general education, I just want to get a good job. (R)

18. I am unable to concentrate well because of restlessness or moodiness. (R)

19.I set high standards for myself in school.

20.I find it hard to pay attention during lectures. (R)

21.I only study the subjects I like. (R)

22.I am distracted from my studies very easily. (R)

23. When work is difficult I either give up or study only the easy parts. (R)

24.I dislike most of the work in my classes. (R)

25 . Worrying about doing poorly interferes with my concentration on tests. (R)

26.I don't understand some course material because I don't listen carefully. (R)

27.I read textbooks assigned for my classes.

28.I feel very panicky when I take an important test. (R)

29. I concentrate fully when studying. 
30.I get so nervous and confused when taking an examination that I fail to answer questions to the best of my ability. (R)

31. My mind wanders a lot when I study. (R)

32.In my opinion, what is taught in my courses is not worth learning. (R)

Note: The final score for the ten separate dependent measures is the addition of items 2,8,10, $13,17,21,24,32$ for the ATTENTION composite; items 5, 7, 9, 12, 15, 19, 23, 27 for the MOTIVATION composite; items 1, 4, 11, 14, 16, 25, 28, 30 for the ANXIETY composite; items $3,6,18,20,22,26,29,31$ for the CONCENTRATION composite. The items with (R) following were reversed scored. Higher scores, therefore, indicate better learning styles. 
Measure 8: The Trauma Symptom Checklist (TSC-33) (Briere \& Runtz 1989)

1. Insomnia (trouble getting to sleep)

$$
\begin{aligned}
& \text { SCALE } \\
& \text { A - Never } \\
& \text { B - Occasionally } \\
& \text { C - Fairly Often } \\
& \text { D - Very Often }
\end{aligned}
$$

2. Restless sleep

3. Nightmares

4. Waking up early in the morning and can't get back to sleep

5. Weight loss(without dieting)

6. Feeling isolated from others

7. Loneliness

8. Low sex drive

9. Sadness

10. "Flashback" (sudden, vivid, distracting memories)

11. "Spacing out" (going away in your mind)

12. Headaches

13. Stomach problems

14. Uncontrollable crying

15. Anxiety attacks

16. Trouble controlling temper

17. Trouble getting along with others

18. Dizziness

19. Passing out

20. Desire to physically hurt yourself

21 . Desire to physically hurt others

22. Sexual problems

23. Sexual over activity

24. Fear of men

25. Fear of women

26. Unnecessary or over-frequent washing

27 . Feelings of inferiority

28. Feelings of guilt

29. Feelings that things are "unreal"

30. Memory problems

31 . Feelings that you are not always in your body

32. Feeling tense all the time

33. Having trouble breathing

Note: The final score for the five separate dependent measures is the mean of items $10,11,18$, $29,30,31$, for the DISSOCIATION composite; items $12,13,15,18,24,25,26,32,33$ for the ANXIETY composite; items 1, 4, 5, 8, 9, 14, 20, 27, 28 for the DEPRESSION composite; items $3,10,22,24,29,30$ for the PSAT-h composite; items 1, 2, 3, 4 for the SLEEP DISTURBANCE composite. Higher scores, therefore, indicate greater symptomatology. 
Measure 9: Sexual Assertiveness Scale (Quina, Harlow, Gibson, \& Morokoff, 1990)

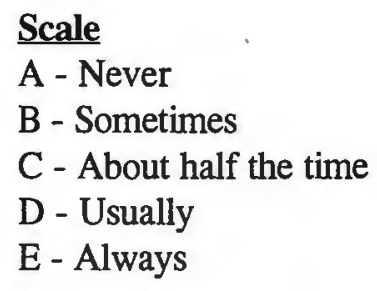

1. I let my partner know if I want my partner to touch my genitals.

2. I refuse to put my mouth on my partner's genitals if I don't want to, even if my partner insists.

3. I have sex without a condom or latex barrier if my partner doesn't like them, even if I want to use one. (R)

4. I begin sex with my partner if I want to.

5. I put my mouth on my partner's genitals if my partner wants me to, even if I don't want to. (R)

6. I make sure my partner and I use a condom or latex barrier when we have sex.

7. I give in and kiss if my partner pressures me, even if I already said no. (R)

8. I wait for my partner to touch my breasts instead of letting my partner know that's what I want. (R)

9. I let my partner kiss my genitals if my partner wants to, even if I don't want to. (R)

10.I wait for my partner to touch my genitals instead of letting my partner know that's what I want. (R)

11. Women should wait for men to start things like breast touching. (R)

12.I let my partner know if I want to have my genitals kissed.

13.I insist on using a condom or latex barrier if I want to, even if my partner doesn't like them.

14.I have sex without using a condom or latex barrier if my partner insists, even if I don't want to. (R)

15.If I said no, I won't let my partner kiss my genitals even if my partner pressures me.

16.I have sex without using a condom or latex barrier if my partner wants. (R)

17.I refuse to have sex if my partner refuses to use a condom or latex barrier.

18.I refuse to let my partner touch my breasts if I don't want that, even if my partner insists.

Note: The final score for the three separate dependent measures is the mean of items $1,4,8,10$, 11,12 , for the INITIATION composite; items $2,5,7,9,15,18$, for the REFUSAL composite; items $3,6,13,14,16,17$, for the BIRTH CONTROL composite. The items with (R) following were reversed scored. Higher scores, therefore, indicate greater sexual assertiveness range from 1 to 5 . 
Measure 10: Sexual Communication Scale (Dieter, 1993 )

\author{
$\underline{\text { Scale }}$ \\ A - Never \\ B - Sometimes \\ C - About half the time \\ D - Usually \\ E - Always
}

1. I would ask if I want to know if my partner ever had a sexually transmitted disease (STD).

2. I would ask if I want to know if my partner ever had an HIV test.

3. I would ask my partner about the AIDS risk of his or her past partners, if I want to know.

4. I would ask if I want to know if my partner ever used needles to take drugs.

5. If I want to know, I would ask my male partner if he ever had sex with a man.

6. I would ask if I want to know if my partner ever had sex with someone who shoots drugs with a needle.

7. I let my partner know what I do not like in sex.

8. I let my partner know how I like to be touched.

9. I let my partner know if I want my partner to keep doing something I like in sex.

10.I let my partner know if my partner does not please me in sex.

11.I tell my partner to stop if my partner touches me in a way I don't like.

12.I let my partner know what feels good to me in sex.

Note: The final score for the two separate dependent measures is the mean of items $1,2,3,4,5$, 6, for the INFORMATION COMMUNICATION composite; and items 7, 8, 9, 10, 11, 12, for the PREFERENCE COMMUNICATION composite. Higher scores, therefore, indicate greater sexual communication range from 1 to 5 . 
Measure 11: Sexual Abuse Inventory (Finkelhor 1974)

As children, many women were in sexual situations with someone older than them. A sexual situation could mean someone showing their genitals to you. It could mean someone touching you in a sexual way. It could also mean someone putting his penis in your mouth, vagina, or rectum. Think back to when you were a child up to the age of 17 with someone who was 5 years older and answer the following questions. Please check your answer. If these questions are upsetting and you want to talk, please use the phone numbers in the front of the survey.

We would like you to try to remember sexual situations you had while growing up. By "sexual," we mean a broad range of things, anything from playing "doctor" to sexual intercourse -- in fact, anything that might have seemed "sexual" to you.

1. Did you have any of the following situations (Before the age of 17) when you were younger. (Check any that apply)

a. An invitation or request to do something sexual.

b. Kissing and hugging in a sexual way.

c. Another person showing his/her sex organs to you .

d. You showing your sex organs to another person.

e. Another person fondling you in a sexual way.

f. You fondling another person in a sexual way.

g. Another person touching your sex organs.

h. You touching another person's sex organs.

i. Intercourse, but without attempting penetration

j. Intercourse.

k. Never had a sexual situation.

1. Other : 
Now we want to ask you to think of one sexual situation, that you had as a child UNDER the age of TWELVE with an adult 5 years older including strangers, friends, or family member like cousins, aunts, uncles, brothers, sisters, mother, or father.

1. Check here if no such situation.

2. About how old were you at the time?

3. About how old was the other person?

4. Was the other person: Male ___ Female

5. Was the other person:

A cousin

A sister

A stepmother

6. What happened (Check
An uncle or aunt

A father

A stranger

A. An invitation or request to do something sexual

B. Kissing and hugging in a sexual way

C. Other person showing his/her sex organ to you

D. You showing your sex organs to other person.

E. Other person fondling you in a sexual way.

F. You fondling another person in a sexual way.

G. Another person touching your sex organs.

H. You touching another person's sex organs.

I. Intercourse, but without attempting penetration.

J. Intercourse.

K. Other (please describe):

A grandparent

A stepfather

A brother

A friend A mother

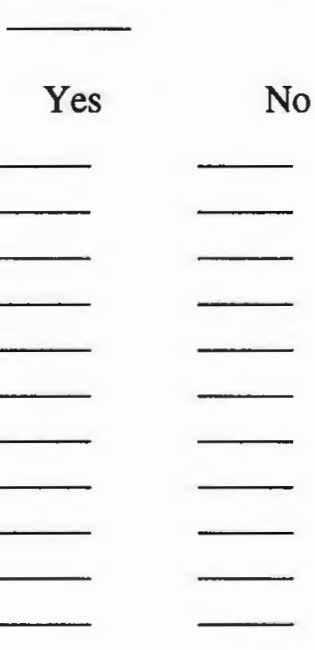

7. Did the other person threaten or force you? Yes
8. If yes how much?
A little
A lot

9. Had the other person been drinking alcohol? Yes

10. About how often were you in a sexul situation with

Once

Seldom

A Few times

11. Over how long a period of time did this go on?

12. Which of these would best describe your reaction at the time of the situation?

Fear __ Shock ___ Surprise ___ Interest ____ Pleasure

13. Who did you tell about this situation, if anyone?

No one

Mother

Father

Other

14. How old were you when you told?

15. In retrospect, would you say this situation was:

Positive Mostly positive Neutral
Other adult

Brother/sister

Friend 
Now we want to ask you to think of one sexual situation, that you had as a child OVER the age of TWELVE with an adult $\underline{5}$ years older including strangers, friends, or family member like cousins, aunts, uncles, brothers, sisters, mother, or father.

1. Check here if no such situation.

2. About how old were you at the time?

3. About how old was the other person?

4. Was the other person:

Male

Female

5. Was the other person:

A cousin

A sister

An uncle or aunt

A stepmother

A father

A stranger

6. What happened (Check A for Yes or B for No)

A. An invitation or request to do something sexual

B. Kissing and hugging in a sexual way

C. Other person showing his/her sex organ to you

D. You showing your sex organs to other person.

E. Other person fondling you in a sexual way.

F. You fondling another person in a sexual way.

G. Another person touching your sex organs.

H. You touching another person's sex organs.

I. Intercourse, but without attempting penetration.

J. Intercourse.

K. Other (please describe):

A grandparent A stepfather

A brother

A mother

A friend

7. Did the other person threaten or force you? Yes

8. If yes how much? A little

A lot

9. Had the other person been drinking alcohol? Yes

10. About how often were you in a sexual situation with this person?

Once Seldom

A Few times Often

11. Over how long a period of time did this go on?

12. Which of these would best describe your reaction at the time of the situation?

Fear Shock Surprise 13. Who did you tell about this situation, if anyone? Interest Pleasure

No one

Other adult

Mother

Brother/sister

Father

Friend

Other

14. How old were you when you told?

15. In retrospect, would you say this situation was:

Positive

Mostly positive

Neutral

Mostly negative

Negative 


\section{Measure 12: Transtheretical Model Staging Questions}

Please only check one answer.

1. Have you ever attempted to work on a problem in counseling?

YES, I have for MORE than 6 months.

YES, I have, but for LESS than 6 months.

$\mathrm{NO}$, but $\mathrm{I}$ intend to in the next 30 days.

$\mathrm{NO}$, but $\mathrm{I}$ intend to in the next 6 months.

$\mathrm{NO}$, and I do NOT intend to in the next $\overline{6 \text { months. }}$.

Note: The final score for the five separate dependent measures item more than 6 month for the MAINTENANCE stage; item less than 6 months for the ACTION stage; item next 30 days for the PREPARATION stage; item next 6 months for the CONTEMPLATION stage; and item not next 6 months for the PRECONTEMPLATION stage.

Transtheretical model staging question for sexual abuse problem

Please only check one answer.

1. Have you attempted to work on your sexual abuse issues?

YES, I have been for MORE than 6 months.

YES, I have been, but for LESS than 6 months.

NO, but $I$ intend to in the next 30 days.

$\mathrm{NO}$, but I intend to in the next 6 months.

$\mathrm{NO}$, and I do NOT intend to in the next 6 months.

Note: The final score for the five separate dependent measures item more than 6 month for the MAINTENANCE stage; item less than 6 months for the ACTION stage; item next 30 days for the PREPARATION stage; item next 6 months for the CONTEMPLATION stage; and item not next 6 months for the PRECONTEMPLATION stage. 
Measure 13: Social Support (Vaux, Riedel, \& Stewart 1987)

People help each other out in a lot of different ways. Suppose you had some kind of problem (were upset about something, were broke, or needed some advice or guidance), how likely would members of your family be to help you out in each of the specific ways listed below. We realize you may rarely need this kind of help, but if you did would your family help in the ways indicated. Try to base your answers on your past experience with these people. Use the scale below and fill in the letter on the scantron sheet that corresponds to the number of the question.

\author{
SCALE \\ A - No one would do this \\ B - Someone might do this \\ C - Some family members would probably do this \\ D - Some family would certainly do this \\ E - Most family members would certainly do this
}

1. Would comfort me if I was upset.

2. Would joke around or suggest doing something to cheer me up.

3. Would suggest how I could find out more about a situation.

4. Would listen if I needed to talk about my feelings.

5. Would pay for my lunch if I was broke.

6. Would suggest a way I might do something.

7. Would give me encouragement to do something different.

8. Would give me advice about what to do.

9. Would help me figure out what I wanted to do.

10. Would show me that they understood how I was feeling.

11. Would buy me a drink if I was short of money.

12. Would help me decide what to do.

13. Would give me a hug, or otherwise show me I was cared about.

14. Would help me figure out what was going on.

15. Would help me out with some necessary purchase.

16. Would not pass judgment on me.

17. Would tell me who to talk to for help.

18. Would loan me money for an indefinite period.

19. Would be sympathetic if I was upset.

20. Would stick by me in a crunch.

21 . Would buy me clothes if I was short of money.

22. Would tell me about the available choices and options.

23. Would give me reasons why I should or should not do something.

24. Would show affection for me.

25. Would bring me little presents or things I needed.

26. Would tell me the best way to get something done.

27. Would loan me money and want to "forget about it"

28. Would tell me what to do.

29. Would help me think about a problem.

30. Would loan me a fairly large sum of money (say the equivalent of a month's rent or mortgage). 


\title{
Answers these questions with your friends in mind.
}

Suppose you had some kind of problem (were upset about something, were broke, or needed some advice or guidance), how likely would your friends be to help you out in each of the specific ways listed below. We realize you may rarely need this kind of help, but if you did would Friends help in the ways indicated. Try to base your answers on your past experience with these people. Use the scale below and fill in the letter on the scantron sheet that corresponds to the number of the question.

\author{
SCALE \\ A - No one would do this \\ B - Someone might do this \\ C - Some friends would probably do this \\ D - Some friends would certainly do this \\ E - Most friends would certainly do this
}

31. Would comfort me if I was upset.

32. Would joke around or suggest doing something to cheer me up.

33. Would suggest how I could find out more about a situation.

34. Would listen if I needed to talk about my feelings.

35. Would pay for my lunch if I was broke.

36. Would suggest a way I might do something.

37. Would give me encouragement to do something different.

38. Would give me advice about what to do.

39. Would help me figure out what I wanted to do.

40. Would show me that they understood how I was feeling.

41. Would buy me a drink if I was short of money.

42. Would help me decide what to do.

43. Would give me a hug, or otherwise show me I was cared about.

44. Would help me figure out what was going on.

45. Would help me out with some necessary purchase.

46. Would not pass judgment on me.

47. Would tell me who to talk to for help.

48. Would loan me money for an indefinite period.

49. Would be sympathetic if I was upset.

50 . Would stick by me in a crunch.

51 . Would buy me clothes if I was short of money.

52 . Would tell me about the available choices and options.

53. Would give me reasons why I should or should not do something.

54. Would show affection for me.

55. Would bring me little presents or things I needed.

56. Would tell me the best way to get something done.

57. Would loan me money and want to "forget about it"

58. Would tell me what to do.

59. Would help me think about a problem. 
60. Would loan me a fairly large sum of money (say the equivalent of a month's rent or mortgage).

Note: The final score for the two separate dependent measures is the addition of items 1, 2, 4, 7, $10,13,16,19,20,24$ for the FAMILY EMOTIONAL SUPPORT composite; items 31, 32, 34, 37, 40, 43, 46, 49, 50, 54 for the FRIEND EMOTIONAL SUPPORT composite; items 5, 11, $15,18,21,25,27,30$ for the FAMILY FINANCIAL SUPPORT composite; items 35, 41, 45, $48,51,55,57,60$ for the FRIEND FINANCIAL SUPPORT composite; items 3, 6, 8, 9, 12, 14 , 17, 22, 23, 26, 28, 29 for the FAMILY ADVICE/GUIDANCE SUPPORT composite; and items $33,36,38,40,42,44,47,52,53,56,58,59$ for the FRIEND ADVICE/GUIDANCE

SUPPORT composite. Higher scores, therefore, indicate greater social support. 


\section{Bibliography}

Betz, W., Petretic-Jackson, P., Katsikas, S., Ames, D., Pitman, L., Lawless, M (1993). Effects of child abuse experiences on dimensions of adult self-esteem. Paper presented at APA

Bell, C. C., \& Jenkins, E. J. (1991). Traumatic stress and children. Third National conference: Health care for the poor and underserved "children at risk". Journal of Health Care for the Poor and Underserved, 2, 175-185.

Birnbaum, R. (1972). Factors associated with the accuracy of self-reported high school grades. Psychology in the Schools, 9, 364-370.

Blum, R. W., Harmon, B., Harris, L., Bergeisen, L., \& Resnick, M. D. (1992). American Indian-Alaska native youth health. Journal of American Medical Association, 267. 1637-1644.

Bosco, J. J., Robin, M. R., (1980). Hyperkiness: Prevalence and treatment. In: Whalen CK, Henker, M., eds. Hyperactive Children. New York: Academic Press, 173-86.

Briere, J., \& Runtz, M. (1986). Adolescent "acting-out" and childhood history of sexual abuse. Journal of Interpersonal Violence, 1. 326-334.

Briere, J., \& Runtz, M. (1988). Symptomatology associated with childhood sexual victimization in a nonclinical adult sample. Child Abuse \& Neglect, 12, 51-59. Briere, J., \& Runtz, M. (1988). Multivariate correlates of childhood psychological and physical maltreatment among university women. Child Abuse \& Neglect. 12, 331-341. 
Briere, J., \& Runtz, M. (1989). The Trauma Symptom Checklist (TSC-33) early data on a new scale. Journal of Interpersonal Violence, 4 , 151-163.

Briere, J (1992). Child Abuse Trauma. Sage Publications: California.

Bushnell, J. A., Wells, J. E., \& Oakley-Browne, M. A. (1992). Long term effects of intrafamilial sexual abuse in childhood. Acta Psychiatrica Scandinavica. 85. 136-142.

Cohen, J. A., \& Mannarino, A. P. (1988). Psychological symptoms in sexually abused girls. Child Abuse and Neglect, 12, 571-577.

The College Board. (1993). SAT program guide for high schools and colleges. (Library of Congress Catalog Card Number 67-27011). Princeton, New Jersey: College Entrance Examination Board

Conte, J. R. \& Schuerman,-J. R. (1987). Factors associated with an increased impact of child sexual abuse. Child Abuse and Neglect, 11, 201-211.

Cupoli, J. M., \& Sewell, P. M. (1988). One thousand fifty nine children with a chief complaint of sexual abuse. Child Abuse and Neglect, 12, 151-162.

Deltaglia, L. (1990). Victims and perpetrators of sexual abuse: A psychosocial study from France. Child Abuse and Neglect, 14, 445-447.

Dill, D. L., Chu, J. A., Grob, M. C., \& Eisen, S. V. (1991). The Reliability of abuse history reports: A comparison of two inquiry formats. Comprehensive Psychiatry, 32, 166-169.

Donlon, T. F (1984). The college board technical handbook for the Scholastic Aptitude Test and achievement tests. College Entrance Examination Board. New York 
Dube, R., \& Hebert, M. (1988). Sexual abuse of children under 12 years of age: A review of 511 cases. Child Abuse and Neglect, 12, 321-330.

Egeland, B., Sroufe, L. A., \& Erickson, M. (1983). The developmental consequences of different patterns of maltreatment. Child Abuse and Neglect, 7, 459469.

Einbender, A. J., \& Friedrich, W. N. (1989). Psychological functioning and behavior of sexually abused girls. Journal of Consulting and Clinical Psychology, 57. 155-157.

Elliott, D. M., \& Briere, J. (1992). Sexual abuse trauma among professional women: Validating the Trauma Symptom Checklist 40 (TSC 40). Child Abuse and Neglect, 16, 391-398.

Faller, K. C. (1987). Women who sexually abuse children. Violence and Victims, 2, 263-276.

Faller, K. C. (1989). The role relationship between victim and perpetrator as a predictor of characteristics of intrafamilial sexual abuse. Child and Adolescent Social Work, 6, 217-229.

Farrell, L. T. (1988). Factors that affect a victim's self-disclosure in fatherdaughter incest. Child-Welfare, $67,462-468$.

Friedrich, W. N., Urquiza, A .J., \& Beilke, R. L. (1986). Behavior problems in sexually abused young children. Journal of Pediatric Psychology, 11, 391-402.

Friedrich, W. N., Grambsch, P., Damon, L, \& Hewitt, S. K., Koverola, C., Lang, R.A., Wolfe, V., \& Broughton, D. (1992). Child Sexual Behavior Inventory: Normative and clinical comparisons. Psychological-Assessment, 4, 303-311. 
Finkelhor, D. (1979). Sexually Victimized Children. Free Press. New York.

Finkelhor, D., Hotaling, G., Lewis, I. A., \& Smith, C. (1990). Sexual abuse in a national survey of adult men and women: Prevalence, characteristics, and risk factors. Child Abuse and Neglect, 14, 19-28.

Frude, N. (1982). The sexual nature of sexual abuse: A review of the literature. Child Abuse and Neglect, 6, 211-223.

German, D. E., Habenicht, D. J., \& Futcher, W. G. (1990). Psychological profile of the female adolescent incest victim. Child Abuse and Neglect, 14, 429-438.

Gidycz, C. A., \& Koss, M. P. (1989). The impact of adolescent sexual victimization: Standardized measures of anxiety, depression, and behavioral deviancy. Violence and Victims, 4, 139-149.

Gittelman, R., Mannuzza, S., Shenker, R., Bonagura, N. (1985). Hyperactive boys almost grown up. I. Psychiatric status. Archives General Psychiatry, 42, 937-947

Goldman, B. A., Flake, W. L. \& Matheson, M. B. (1990). Accuracy of college students' perceptions of their SAT scores, high school and college grade point averages relative to their ability. Perceptual and Motor Skills, 70, 514.

Goldston, D. B., Turnquist, D. C., \& Knutson, J. F. (1989). Presenting problems of sexually abused girls receiving psychiatric services. Journal of Abnormal Psychology, 98, 314-317.

Grayston, A. D., de Luca, R. V., \& Boyes, D. A. (1992). Self esteem, anxiety, and loneliness in preadolescent girls who have experienced sexual abuse. Child Psychiatry and Human Development, 22, 277-286. 
Hibbard, R. A., \& Hartman, G. L. (1992). Behavioral problems in alleged sexual abuse victims. Child-Abuse-and-Neglect, 16, 755-762.

Hubbard, G. B. (1989). Mothers' perceptions of incest: Sustained disruption and turmoil. Archives-of-Psychiatric-Nursing, 3, 34-40.

Hunter, M. (1990). Abused boys: The neglected victims of sexual abuse. Ballantine Books. New York.

Hunter, R. S., Kilstrom, N. \& Loda, F. (1985). Sexually abused children: Identifying masked presentation in a medical setting. Child Abuse and Neglect. 9, 17 25.

Jaudes, P. K., \& Morris, M. (1990). Child sexual abuse: Who goes home? Child Abuse and Neglect. 14, 61-68.

Loftus, E F. (1993). The reality of repressed memories. American Psychologist. 48, 518-537.

Lusk, R. N., Waterman, J. M., Kelly, R. J., McCord, J., \& Oliveri, M. K. (1993). School-related differences in ritually and non-ritually sexually abused children. Paper presented at APA.

Malinosky-Rummell, R. R., \& Hoier, T. S. (1991). Validating measures of dissociation in sexually abused and nonabused children. Behavioral Assessment, 13. 341-357.

Mann, E. M. (1985). The assessment of credibility of sexually abused children in criminal court cases. American journal of Forensic Psychiatry, 6, 9-15.

Mannarino, A. P., \& Cohen, J. A. (1986). A clinical demographic study of sexually abused children. Child Abuse and Neglect, 10, 17-23. 
Margolin, L. (1992). Sexual abuse by grandparents. Child Abuse and Neglect. 16. 735-741.

Mrazek, P. J., Lynch, M.A., \& Bentovim, A. (1983). sexual abuse of children in the United Kingdom. Child Abuse and Neglect, 7, 147-153.

Neemann, J., \& Harter, S. (1986). Manual for the Self-Perception Profile for College Students. Denver, CO: University of Denver.

Ney, P. G. (1988).Transgenerational child abuse. Child Psychiatry and Human Development, 18, 151-168.

Perry, M. A., Doran, L. D., \& Wells, E. A. (1983). Developmental and behavioral characteristics of the physically abused child. Journal of Clinical Child Psychology, 12, 880-886.

Petretic-Jackson, P., Pitman, L., Betz, W., Katsikas, S., Ames, D., Lawless, M. (1993). Defining childhood psychological maltreatment: Effects of gender and victim status. Paper presented at APA.

Plante, T. G., Goldfarb, L., \& Wadley, V. (1993). Are stress and coping associated with aptitude and achievement testing performance among children? A preliminary investigation. Journal of School Psychology, 31, 259-266.

Rao, K., DiClemente, R. J., \& Ponton, L. E.(1992). Child sexual abuse of Asians compared with other populations. Journal of the American Academy of Child and Adolescent Psychiatry, 31, 880-886.

Reymone, N. D., (1993). A comparison of the school performance of sexually abused, neglected and non-maltreated children. Child study Journal, 23 , 17-39. 
Risin, L. I., McNamara, J. R. (1989). Validation of child sexual abuse: The psychologist's role. Journal of Clinical Psychology, 45, 175-184.

Rosenthal, J. A. (1988). Patterns of reported child abuse and neglect. Child Abuse and Neglect, 12, 263-271.

Runtz, M., \& Briere, J. (1986). Adolescent acting out and childhood history of sexual abuse. Journal of Interpersonal Violence, 1, 326-334.

Rust, J. O., \& Troupe, P. A. (1991). Relationships of treatment of child sexual abuse with school achievement and self concept. Journal of Early Adolescence, 11. 420-429.

Sandberg, D. A., \& Lynn, S. J. (1992). Dissociative experiences, psychopathology and adjustment, and child and adolescent maltreatment in female college students. Journal of Abnormal Psychology, 101, 717-723.

Sawyer, R., Laing, J., Houston, W. (1989) Accuracy of self-reported high school courses and grades of college-bound students. College and University, 64, 28899.

Sauzier, M. (1989). Disclosure of child sexual abuse: For better or for worse. Psychiatric Clinics of North America, 12, 455-469.

Schiller, P. (1988). Survey of the effects of incest on adult survivors. Response to the Victimization of Women and Children, 11, 16-18.

Silver, L. B., (1986). Learning disabilities: the primary care role in multidisciplinary management. Post Grad Med, 79 285-296.

Sirles, E. A., \& Franke, P. J. (1989). Factors influencing mothers' reactions to intrafamily sexual abuse. Child-Abuse-and-Neglect, 13, 131-139. 
Sorensen, T., \& Snow, B. (1991). How children tell: The process of disclosure in child sexual abuse. Child-Welfare, 70, 3-15.

Stinson, M. H., \& Hendrick, S. S. (1992). Reported childhood sexual abuse in university counseling center clients. Journal of Counseling Psychology, 39, 370-374.

Stricker, L. J. (1991). Current validity of 1975 and 1985 SATs: Implications for validity trends since the mid-1970's. Journal of Educational Measurement, 28, 93-98.

Tsai, M., Feldman-Summers, S., \& Edgar, M. (1979). Childhood Molestation: Variables related to different impacts on psychosexual functioning. Journal of Abnormal Psychology, 88, 407-417.

Thoennes, N. \& Tjaden, P. G. (1990). The extent, nature, and validity of sexual abuse allegation in custody/visitation disputes. Child abuse and Neglect, 14, 151-163

Tong, L., Oates, K., McDowell, M. (1987). Personality development following sexual abuse. Special Issue: Child abuse and neglect. Child Abuse and Neglect, 11 . 371-383.

Vaux, A., Riedel, S., \& Stewart, D. (1987). Modes of social support: The social support behaviors (SS-B) scale; American Journal of Community. Psychology. 15, 209237.

Weinstein, C. E., Palmer, D.R., \& Schulte, A.C. (1987). Learning and Study Strategies Inventory. H \& H Publishing Co.: Florida.

Whitehead, T. M.(1992). Application of the delayed discovery rule: The only hope for justice for sexual abuse survivors. Law and Psychology Review, 16, 153-170.

Witchel, R. I. (1991). College student survivors of incest and other child sexual abuse. New Directions for Student Services, 54, 63-76. 
Wyatt, G. E., \& Peters, S. D. (1986). Issues in the definition of child sexual abuse in prevalence research. Child Abuse and Neglect. 10, 231-240.

Wyatt, G. E., \& Mickey, M. R. (1987). Ameliorating the effect of child sexual abuse. Journal of Interpersonal Violence, 2. 403-414. 